\title{
Modeling of Purchase and Sales Contracts in Supply Chain Optimization
}

\author{
Minhwan Park and Sunwon Park \\ Department of Chemical and Biomolecular Engineering, Korea Advanced Institute of Science and \\ Technology, 373-1 Guseong-dong, Yuseong-gu, Daejeon 305-701, Republic of Korea \\ Fernando D. Melle and Ignacio E. Grossmann* \\ Department of Chemical Engineering, Carnegie Mellon University, 5000 Forbes Avenue, Pittsburgh, \\ Pennsylvania 15213-3890, USA
}

*CORRESPONDING AUTHOR: Ignacio Grossmann grossmann@cmu.edu, (412)268-3642

\begin{abstract}
This work presents a novel approach for modeling of different types of contracts that a company may sign with its suppliers and customers. The main objective is to expand the scope of current planning and supply chain optimization models by including the selection of the types of contracts as an additional decision. The solution approach relies on representing the decision of choosing different contracts using disjunctive programming for both short-term and long-term production planning models. The resulting formulation is converted into a mixed-integer linear programming (MILP) problem. The advantages of the proposed models are highlighted in two case studies of increasing complexity.
\end{abstract}

Keywords: Supply Chain Management, Supply Chain Optimization, MILP, Purchase and Sales, Contract 


\section{Introduction}

If we examine the ever increasing amount of literature on problems belonging to the operation planning of production plants and Supply Chain Management (SCM), it can be found that there are still many issues related to the management of the relationships between a company's Supply Chain (SC) and its customers and suppliers. Particularly, the signing of contracts is a common practice in the business world, through which the company aims mainly for two objectives: to reduce uncertainty by planning capacity and ensuring a certain sales level, and to take advantage of the discounts for purchasing materials in large amounts (economies of scale). For example, on reviewing the advances and challenges in SCM, Shah (2005) ${ }^{1}$ identifies the negotiation of long-term contracts as an important SCM problem at a strategic level.

A contract can be understood as a binding agreement in which the seller provides the specified product and the buyer pays for it under specific terms and conditions. Current approaches for production planning at different levels often neglect this important aspect focusing on other issues ${ }^{2}$. Therefore, in this work, we propose the modeling of several types of contracts with the external entities of the company, both suppliers and customers, which gives the opportunity of improving these approaches.

The paper is organized as follows. First, a literature review on recent work about contract modeling is presented. Next, the problem is described as well as the proposed models for process network with extensions to allow for contracts. These models are solved bye means of disjunctive programming (Grossmann and Lee $\left.(2003)^{3}\right)$. The performance of the models is then illustrated through two examples and finally, the results obtained are discussed and some guidelines for future work are indicated.

\section{Literature review}

Literature on contracts, in the area of SCM, may be divided in three areas: negotiation process, uncertainty management and contract modeling. 
The negotiation process is an area mainly belonging to the field of Computers Science in which the emphasis is placed on the contract negotiation process itself. Many of these works are related to the ecommerce and software agents on the web. Within this area, a number of different negotiable attributes, e.g. prices, quantities, due-dates, etc., are calculated by means of auction-like processes between the interested parties. Such systems are simulators that mimic the negotiation process until reaching an agreement in the contractual conditions (Sandholm $(2002)^{4}$ ). Goodwin et al. (1999) ${ }^{5}$ present a framework for providing decision support for an on-line exchange. They use a multi-agent system to find matches of demand and supply on the exchange and provide the user with the best set of transactions. The user then chooses the best match based on his/her discretion.

Most works devoted to uncertainty management apply an adapter strategy in which the company controls the risk exposure of its assets by constantly adapting its operations to unfolding demand realizations. In contrast, in the strategy known as shaper the SC aims to restructure the demand distribution contracting agreements with the customer (Anupindi and Bassok (1999) ${ }^{6}$ ). Some of these works are aimed at demonstrating how contracts are an effective tool against demand and supply uncertainty. They are based on stochastic programming and use risk measures to compare the approaches with and without signing up contracts. Nevertheless, these works do not put the emphasis on modeling the type of contracts, in fact, contract models are rather simple because they consist of including fixed quantities at given times in the horizon of the analysis.

A type of contract that is extensively used in these works is the option contract (Hull (1995) ${ }^{7}$. Options, also known as derivative securities or contingent claims, are legally binding and negotiable contracts that give the holder the right, but not the obligation, to purchase a certain quantity of an agricultural, industrial, or financial product at a specified price and time for a one-time, upfront premium payment. Applications in this direction can be found in the works by Gupta and Maranas (2003) ${ }^{8}$, Barbaro and Bagajewicz (2004) ${ }^{9}$, Bonfill et al. (2004) ${ }^{10}$ and Aseeri and Bagajewicz (2004) ${ }^{11}$.

A different aspect within the area of contracts is the modeling of different types of contracts that a company can set up during its planning process. The consequence of this is the modification of the 
objective function of the corresponding optimization program resulting in a more complex but also more realistic cost function. There has been little work done in this area and the one that has been reported by Kallrath (2002) $)^{12}$, Schulz et al. (2005) ${ }^{13}$ and Chandra et al. (2004) ${ }^{14}$ assumes that types of contracts are given and not decision variables.

\section{Problem statement}

In this paper, we consider short and long-term multiperiod production planning of a chemical supply chain network. The network involves NP processes, NC chemicals for which NI inventories are kept over NT time periods. The operation of the network is constrained by existing capacities of all processes in the network, limits in the supplies of raw materials and market saturation of some products. Information is given for different types of contracts that can be made for purchasing raw materials and selling the products. The objective in the short-term planning problem is to determine over a given time horizon, typically weeks or months, the types of contracts for the purchase of raw materials and sales of products in order to maximize the profit, which can be calculated by the data on sales revenues, operating costs, marketing costs, inventory cost and shortfall penalties. For the case of the long-term planning problem, we consider the possible capacity expansion of the processes. In this case, we account for the capital costs in the NPV but exclude the effect of inventories since the length of the time periods are assumed to be large (e.g. one year each). Our goal is to decide (a) which contract to make in the purchase of the raw materials and selling the products in each time period, and (b) whether capacity of each process should be expanded or not in each time period.

We consider various models for the supply/demand that involve different contract types which include various types of discounts depending on the volumes and lengths of contracts. We will assume that all the information is available in order to formulate the problem as a multiperiod MILP model.

\subsection{Contract models for supply}


First, we assume that contracts are made only for supplies. The treatment of demands is entirely analogous. The types of contracts that will be considered when purchasing raw materials from suppliers include the following: (1) fixed price, (2) discount after certain amount, (3) bulk discount, and (4) fixed duration.

\section{Fixed price contract:}

A fixed price contract simply means that we buy raw materials in any amount at the current market price. The cost of purchasing raw materials in the fixed price contract is given by:

$$
\operatorname{COST}_{j t}^{f}=\varphi_{j t}^{f} P_{j t}^{f} \quad j \in J R, t \in T
$$

where $\varphi_{j t}^{f}$ is the contract price of raw material $j$ at time period $t$ and $P_{j t}^{f}$ is the amount of raw materials $j$ purchased at time period $t$.

\section{Discount contracts:}

On the other hand, the discount after a certain amount and the bulk discount require the purchase at a minimum quantity of chemical $j$ at time $t$ ( $\sigma_{j t}^{d}$ and $\sigma_{j t}^{b}$, respectively). The difference between them is that the price in discount after $\sigma_{j t}^{d}$ is reduced to amounts that exceed $\sigma_{j t}^{d}$. In contrast bulk contract assumes that if the amount purchased exceeds $\sigma_{j t}^{b}$, then the price is reduced for the entire amount that is purchased. In both cases we assume that we renew the contracts at each time period.

To model the various types of contracts, we use disjunctions in the following models.

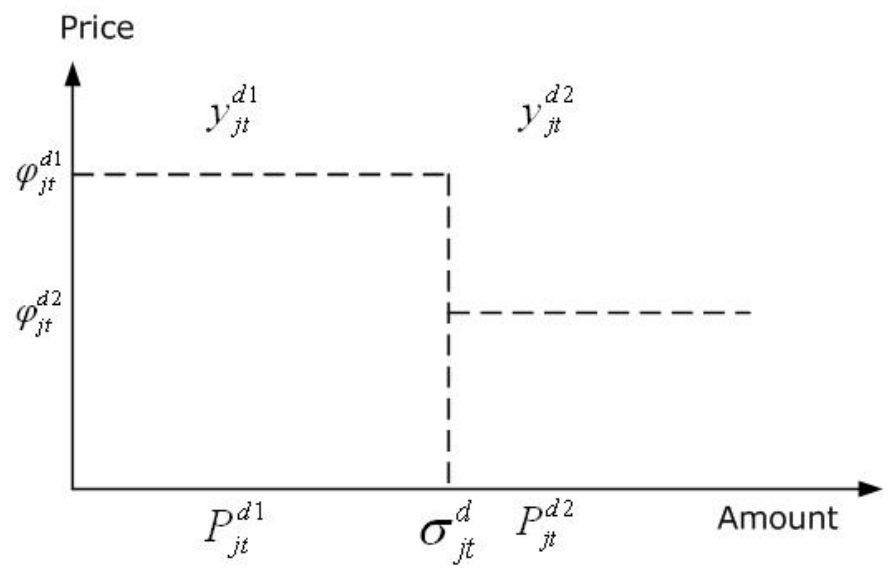

Figure 1. Discount after $\sigma_{j t}^{d}$ amount. 


\section{Discount after a certain amount:}

The cost of purchasing raw materials in the discount after a certain amount (see Figure 1) is given by:

$$
\operatorname{COST}_{j t}^{d}=\varphi_{j t}^{d 1} P_{j t}^{d 1}+\varphi_{j t}^{d 2} P_{j t}^{d 2} \quad j \in J R, t \in T
$$

$\left[\begin{array}{l}y_{j t}^{d 1} \\ 0 \leq P_{j t}^{d 1} \leq \sigma_{j t}^{d} \\ P_{j t}^{d 2}=0\end{array}\right] \vee\left[\begin{array}{l}y_{j t}^{d 2} \\ P_{j t}^{d 1}=\sigma_{j t}^{d} \\ P_{j t}^{d 2} \geq 0\end{array}\right] \quad j \in J R, t \in T$

$P_{j t}^{d}=P_{j t}^{d 1}+P_{j t}^{d 2} \quad j \in J R, t \in T$

where $\varphi_{j t}^{d 1}>\varphi_{j t}^{d 2}$.

In this contract, if the amount of raw material required is $P_{j t}^{d 2}$ which exceeds $\sigma_{j t}^{d}\left(y_{j t}^{d 2}=t r u e\right)$, we buy $\sigma_{j t}^{d}$ of raw materials at the price of $\varphi_{j t}^{d 1}$ and an excess amount, $P_{j t}^{d 2}-\sigma_{j t}^{d}$, at the lower price, $\varphi_{j t}^{d 2}$. Otherwise ( $y_{j t}^{d 1}=$ true ), we buy raw materials at the price of $\varphi_{j t}^{d 1}$ which is higher than $\varphi_{j t}^{d 2}$.

\section{Bulk discount:}

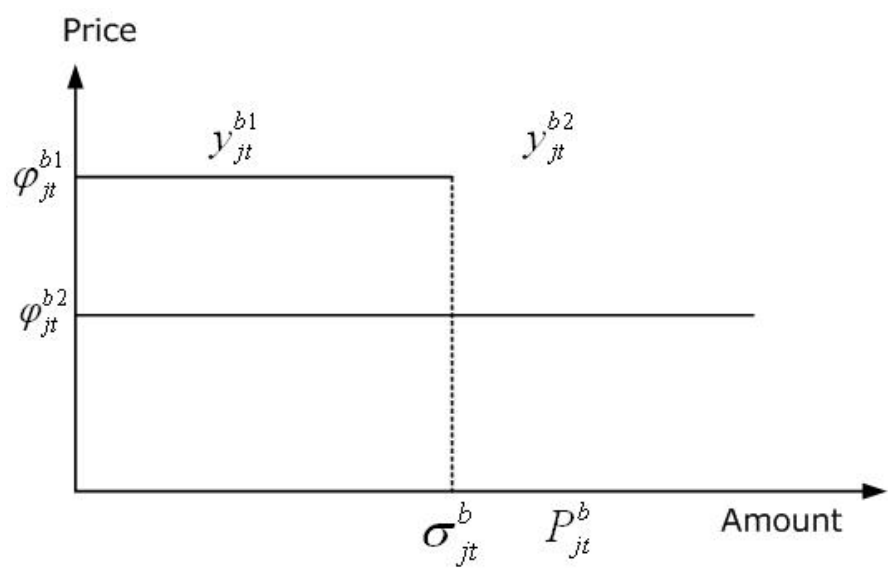

Figure 2. Bulk discount.

The cost of purchasing raw materials in the bulk discount (see Figure 2) is given by:

$$
\left[\begin{array}{l}
y_{j t}^{b 1} \\
\operatorname{COST}_{j t}^{b}=\varphi_{j t}^{b 1} P_{j t}^{b} \\
0 \leq P_{j t}^{b} \leq \sigma_{j t}^{b}
\end{array}\right] \vee\left[\begin{array}{l}
y_{j t}^{b 2} \\
\operatorname{COST}_{j t}^{b}=\varphi_{j t}^{b 2} P_{j t}^{b} \\
P_{j t}^{b} \geq \sigma_{j t}^{b}
\end{array}\right] \quad j \in J R, t \in T
$$


In the bulk discount contract, we buy the entire amount of raw materials at the lower price $\varphi_{j t}^{b 2}$ if the amount of raw materials we buy is greater than $\sigma_{j t}^{b}$. Otherwise, in this contract we purchase the raw material at the higher price $\varphi_{j t}^{b 1}$.

\section{Fixed duration contract:}

The fixed duration contract specifies the length of the time that contracts are valid and the minimum quantity that must be purchased. For example, the 1-month contract specifies no minimum amount at the current price $\left(\varphi_{j t}^{l 1}\right)$ and lasts for 1 month. The 2-month contract specifies a minimum purchase quantity $\left(\sigma_{j t}^{l 2}\right)$ and the purchase price $\left(\varphi_{j t}^{l 2}\right)$ which is lower than $\varphi_{j t}^{l 1}$ for the 2 months. The 3 -month contract specifies the minimum quantity $\left(\sigma_{j t}^{l 3}\right)$ and the purchase price $\varphi_{j t}^{l 3}$ which is lower than $\varphi_{j t}^{l 2}$ during the 3 months. In fixed duration contracts, the longer the contracts last, the larger the minimum purchase quantities per month $\left(0<\sigma_{j t}^{l 2}<\sigma_{j t}^{l 3}\right)$ are, but the lower the purchase prices $\left(\varphi_{j t}^{l 1}>\varphi_{j t}^{l 2}>\varphi_{j t}^{l 3}\right)$ are. Figure 3 shows how each contract lasts during a given number of periods.

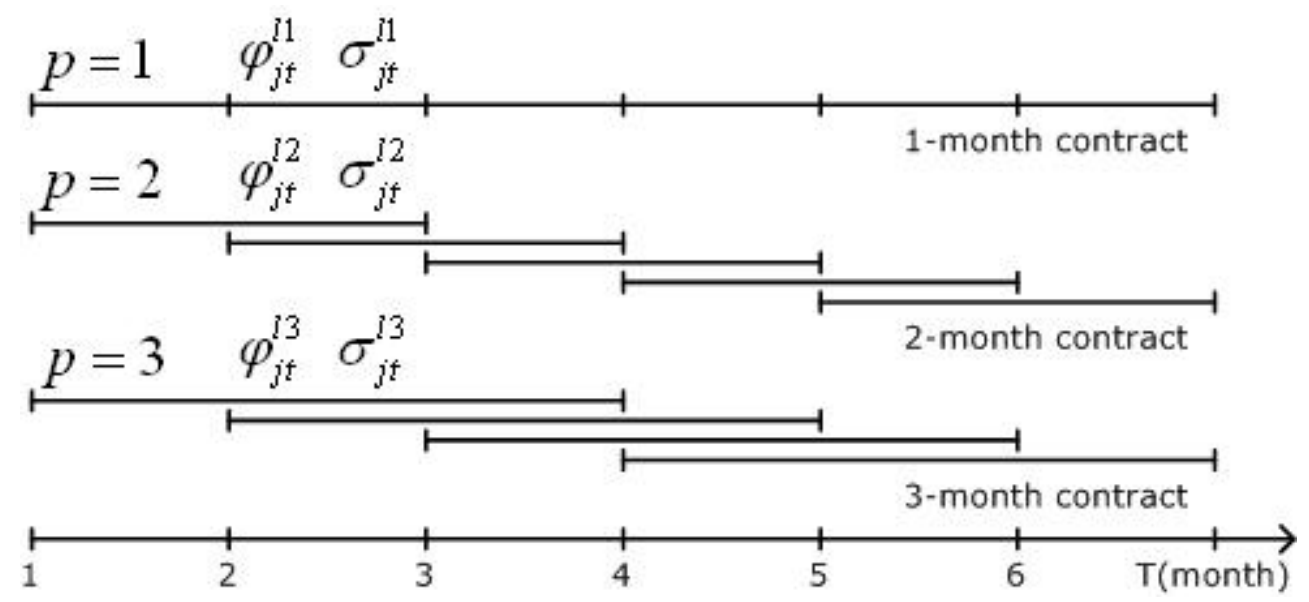

Figure 3. Fixed duration contracts.

The cost of purchasing raw materials in the fixed length contract, assuming up to 3 time periods contract for simplicity, is given by: 


$$
\left[\begin{array}{l}
y_{j t}^{l 1} \\
\operatorname{COS} T_{j t}^{l}=\varphi_{j t}^{l 1} P_{j t}^{l} \\
P_{j t}^{l} \geq \sigma_{j t}^{l 1}
\end{array}\right] \vee\left[\begin{array}{l}
y_{j t}^{l 2} \\
\operatorname{COS} T_{j t}^{l}=\varphi_{j t}^{l 2} P_{j t}^{l} \\
\operatorname{COST}_{j, t+1}^{l}=\varphi_{j t}^{l 2} P_{j, t+1}^{l} \\
P_{j t}^{l} \geq \sigma_{j t}^{l 2} \\
P_{j, t+1}^{l} \geq \sigma_{j t}^{l 2}
\end{array}\right] \vee\left[\begin{array}{l}
y_{j t}^{l 3} \\
\operatorname{COS} T_{j t}^{l}=\varphi_{j t}^{l 3} P_{j t}^{l} \\
\operatorname{COS} T_{j, t+1}^{l}=\varphi_{j t}^{l 3} P_{j, t+1}^{l} \\
\operatorname{COS} T_{j, t+2}^{l}=\varphi_{j t}^{l 3} P_{j, t+2}^{l} \\
P_{j t}^{l} \geq \sigma_{j t}^{l 3} \\
P_{j, t+1}^{l} \geq \sigma_{j t}^{l 3} \\
P_{j, t+2}^{l} \geq \sigma_{j t}^{l 3}
\end{array}\right] j \in J R, t \in T
$$

\subsection{Contract models for demand}

Concerning the contracts with the customers, we also consider the four cases mentioned above. A fixed price contract means that we sell products in some amount with the current market price. The revenues of selling products in the fixed price contract are given by:

$$
R E V_{j t}^{f}=\psi_{j t}^{f} S_{j t}^{f} \quad j \in J P, t \in T
$$

where $\psi_{j t}^{f}$ is the contract price of product $j$ at time period $t$ and $S_{j t}^{f}$ is the amount of $j$ sold at time period $t$. The superscript stands for the type of contract, fixed price contract in this case.

The income for selling products in the discount after certain amount is given by:

$$
\begin{aligned}
& R E V_{j t}^{d}=\psi_{j t}^{d 1} S_{j t}^{d 1}+\psi_{j t}^{d 2} S_{j t}^{d 2} \quad j \in J P, t \in T \\
& {\left[\begin{array}{l}
z_{j t}^{d 1} \\
0 \leq S_{j t}^{d 1} \leq \rho_{j t}^{d} \\
S_{j t}^{d 2}=0
\end{array}\right] \vee\left[\begin{array}{l}
z_{j t}^{d 2} \\
S_{j t}^{d 1}=\rho_{j t}^{d} \\
S_{j t}^{d 2} \geq 0
\end{array}\right] \quad j \in J P, t \in T} \\
& S_{j t}^{d}=S_{j t}^{d 1}+S_{j t}^{d 2} \quad j \in J P, t \in T
\end{aligned}
$$

where $\psi_{j t}^{d 1}>\psi_{j t}^{d 2}$ are the two different prices of product $j$ and $\rho_{j t}^{d}$ is the minimum amount that is necessary to sell to give the discount.

Also similarly to the contract with the suppliers, the revenues of selling products in the bulk discount manner are given by: 
$\left[\begin{array}{l}z_{j t}^{b 1} \\ R E V_{j t}^{b}=\psi_{j t}^{b 1} S_{j t}^{b} \\ 0 \leq S_{j t}^{b} \leq \rho_{j t}^{b}\end{array}\right] \vee\left[\begin{array}{l}z_{j t}^{b 2} \\ R E V_{j t}^{b}=\psi_{j t}^{b 2} S_{j t}^{b} \\ S_{j t}^{b} \geq \rho_{j t}^{b}\end{array}\right] \quad j \in J P, t \in T$

with $\psi_{j t}^{b 1}>\psi_{j t}^{b 2}$.

The earnings for selling product in this type of contract, assuming up to 3 periods contract, are given by:

$$
\left[\begin{array}{l}
z_{j t}^{l 1} \\
R E V_{j t}^{l}=\psi_{j t}^{l 1} S_{j t}^{l} \\
S_{j t}^{l} \geq \rho_{j t}^{l 1}
\end{array}\right] \vee\left[\begin{array}{l}
z_{j t}^{l 2} \\
R E V_{j t}^{l}=\psi_{j t}^{l 2} S_{j t}^{l} \\
R E V_{j, t+1}^{l}=\psi_{j t}^{l 2} S_{j, t+1}^{l} \\
S_{j t}^{l} \geq \rho_{j t}^{l 2} \\
S_{j, t+1}^{l} \geq \rho_{j t}^{l 2}
\end{array}\right] \vee\left[\begin{array}{l}
z_{j t}^{l 3} \\
R E V_{j t}^{l}=\psi_{j t}^{l 3} S_{j t}^{l} \\
R E V_{j, t+1}^{l}=\psi_{j t}^{l 3} S_{j, t+1}^{l} \\
R E V_{j, t+2}^{l}=\psi_{j t}^{l 3} S_{j, t+2}^{l} \\
S_{j t}^{l} \geq \rho_{j t}^{l 3} \\
S_{j, t+1}^{l} \geq \rho_{j t}^{l 3} \\
S_{j, t+2}^{l} \geq \rho_{j t}^{l 3}
\end{array}\right] j \in J P, t \in T
$$




\section{LP and MILP models for process network}

In this section, we consider two types of optimization models for process network, for the short-term planning problem and for the long-term planning problem. In the short-term planning problem we consider the schedule of purchase of raw materials from suppliers, production of products of each process with fixed capacity, inventories of each product, and sales of products. In the long-term planning problem we consider the optimal selection and expansion of processes given time varying forecasts for the demands and prices of chemicals over a long time horizon.

\subsection{Short-term planning model}

The objective function to be maximized is the operating profit of the network over a short-term horizon (e.g. several months) consisting of a set of time periods during which prices and demands of chemicals and costs of operating and inventory can vary. The operating costs for each process are assumed to be proportional to the flow of the main product. The short-term planning model is formulated as a multiperiod LP problem. The indices, sets, parameters, and variables defined in the model are given in the Nomenclature section.

In the short-term planning model, the operating profit is given by $\mathrm{P} 1$ :

$$
\begin{aligned}
\text { PROFIT }= & \sum_{j \in J} \sum_{t \in T} \psi_{j t} S_{j t}-\sum_{j \in J} \sum_{t \in T} \varphi_{j t} P_{j t} \\
& -\sum_{i \in I} \sum_{j \in J M_{i}} \sum_{t \in T} \delta_{i t} W_{i j t}-\sum_{j \in J} \sum_{t \in T} \xi_{j t} V_{j t}-\sum_{j \in J} \sum_{t \in T} \theta_{j t} S F_{j t}
\end{aligned}
$$

where each term accounts for income from sales, purchase cost, operating cost, inventory cost, and shortfall cost, respectively. We can additionally define $\operatorname{COST}_{j t}=\varphi_{j t} P_{j t}$ and $R E V_{j t}=\psi_{j t} S_{j t}$ which respectively represents purchases and sales and will be defined later to account for different contracts.

The amount of chemical $j$ being consumed or produced in process $i$ during period $t$ is represented by the variables:

$$
W_{i j t} \geq 0 \quad i \in I, j \in J_{i}, t \in T
$$

where $J_{i}$ is the set of chemicals involved by process $i$. 
All chemical flows in process $i$ other than the main product are given by the mass balance coefficients. The following equation relates the input to the output of processes:

$$
W_{i j t}=\mu_{i j} W_{i j ' t} \quad i \in I, j \in J_{i}, j^{\prime} \in J M_{i}, t \in T
$$

where $J M_{i}$ is the set of main products of process $i$, and $\mu_{i j}$ are positive constants characteristic of each process $i$.

The amount produced by process $i$ cannot exceed the installed capacity:

$$
W_{i j t} \leq Q_{i t} \quad i \in I, j \in J M_{i}, t \in T
$$

As for the raw materials, intermediates and products, they are expressed by NC nodes of chemicals where purchases and sales are considered on single market. They must satisfy the inequalities:

$$
\left.\begin{array}{l}
a_{j t}^{L} \leq P_{j t} \leq a_{j t}^{U} \\
d_{j t}^{L} \leq S_{j t} \leq d_{j t}^{U}
\end{array}\right\} \quad j \in J, t \in T
$$

where $a_{j t}^{L}, a_{j t}^{U}$ are lower and upper bounds on the availabilities, and $d_{j t}^{L}, d_{j t}^{U}$ are lower and upper bounds on the demands.

Equation (18) corresponds to the mass balance of chemical $j$ in the network which includes the inventory levels $V_{j t}$ :

$$
V_{j, t-1}+\sum_{i \in O_{j}} W_{i j t}+P_{j t}=V_{j t}+\sum_{i \in I_{j}} W_{i j t}+S_{j t} \quad j \in J, t \in T
$$

where $O_{j}$ is defined as the set of processes that produce chemical $j$ and $I_{j}$ as the set of processes that consume chemical $j$.

Production shortfalls with respect to the demands (equation (19)) compensate loss of potential sales which is penalized in the objective function, equation (13).

$$
\begin{aligned}
& S F_{j t} \geq d_{j t}^{U}-S_{j t} \quad j \in J, t \in T \\
& 0 \leq S F_{j t} \leq S F_{j t}^{U} \quad j \in J, t \in T
\end{aligned}
$$

Finally, equations (21) and (22) represent the upper or lower bounds for each variable. 


$$
\begin{aligned}
& V_{j t} \leq V_{j t}^{U} \quad j \in J, t \in T \\
& S_{j t}, P_{j t}, W_{i t}, V_{j t} \geq 0
\end{aligned}
$$

\subsection{Long-term planning model}

In the long-term planning model, we consider the network which includes an existing system as well as potential new processes and chemicals. Also, a finite number of time periods is considered during which prices and demands of chemicals, and investment and operating costs of the processes can vary. The objective function to be maximized is the net present value of the project over the specified horizon in order to determine the capacity expansion for existing processes and sales and purchases of chemicals at each time period. This problem therefore becomes a multiperiod MILP model.

Similarly as in the short term planning model, linear models are assumed for the mass balances in the processes, while fixed-charge cost models are used for the investment cost. Also, limits on the investment cost at each time period can be specified, as well as constraints on the sales and purchases. No inventories will be considered since the length of each time period is assumed to be rather long (e.g. 1 year).

In the formulation of this problem, variable $Q_{i t}$ represents the total capacity of process $i$ that is available in period $t, t=1, \ldots, T$. Parameter $Q_{i 0}$ represents the existing capacity of a process at time $t=0$. Variable $Q E_{i t}$ represents the capacity expansion of process $i$ which is installed in period $t$. If $w_{i t}$ are the 0-1 binary variables which indicate the occurrence of the expansions for each process $i$ at each time period $t$, the constraints that apply are:

$$
\begin{aligned}
& \left.\begin{array}{l}
Q E_{i t}^{L} w_{i t} \leq Q E_{i t} \leq Q E_{i t}^{U} w_{i t} \\
w_{i t} \in\{0,1\}
\end{array}\right\} \quad i \in I, t \in T \\
& Q_{i t}=Q_{i, t-1}+Q E_{i t} \quad i \in I, t \in T
\end{aligned}
$$

In equation (23), $Q E_{i t}^{L}$ and $Q E_{i t}^{U}$ are lower and upper bounds for the capacity expansions. A zero-value of the binary variables $w_{i t}$ makes the capacity expansion at period $t$ zero, $Q E_{i t}=0$. If the binary 
variable is equal to one, the capacity expansion is implemented. Equation (24) simply defines the total capacity $Q_{i t}$ that is available at each time period $t$. Equations (14)-(17) are also considered as constraints.

$$
\begin{aligned}
& W_{i j t} \geq 0 \quad i \in I, j \in J_{i}, t \in T \\
& W_{i j t}=\mu_{i j} W_{i j t} \quad i \in I, j \in J_{i}, j^{\prime} \in J M_{i}, t \in T \\
& W_{i j t} \leq Q_{i t} \quad i \in I, j \in J M_{i}, t \in T \\
& \left.\begin{array}{l}
a_{j t}^{L} \leq P_{j t} \leq a_{j t}^{U} \\
d_{j t}^{L} \leq S_{j t} \leq d_{j t}^{U}
\end{array}\right\} \quad j \in J, t \in T
\end{aligned}
$$

Equation (18) is modified into equation (25) since there in no inventory in this problem.

$$
\sum_{i \in O_{j}} W_{i j t}+P_{j t}=\sum_{i \in I_{j}} W_{i j t}+S_{j t} \quad j \in J, t \in T
$$

Finally, the objective function is given by P2:

$$
\begin{aligned}
N P V & =\sum_{j \in J} \sum_{t \in T} \psi_{j t} S_{j t}-\sum_{j \in J} \sum_{t \in T} \varphi_{j t} P_{j t} \\
& -\sum_{i \in I} \sum_{j \in J M_{i}} \sum_{t \in T} \delta_{i t} W_{i j t}-\sum_{i \in I} \sum_{t \in T}\left(\alpha_{i t} Q E_{i t}+\beta_{i t} w_{i t}\right)
\end{aligned}
$$

where $\psi_{j t}, \varphi_{j t}$ are the prices of sales and purchases of the chemical $j, \delta_{i t}$ is the unit operating cost, and parameters $\alpha_{i t}, \beta_{i t}$ express the variable and fixed terms for the investment cost, respectively. All these parameters are discounted at the specific interest rate and include the effects of taxes and depreciations in the net present value.

In order to determine the optimal planning of the network, the multiperiod MILP model consists of maximizing the NPV in equation (26), subject to constraints (14)-(17) and (23)-(25).

We consider additional constraints that include limits on the number of expansions of each process in equation (27) and limit on the capital for investment during each time in equation (28).

$$
\sum_{t} w_{i t} \leq N E X P(i) \quad i \in I
$$


$\sum_{i \in I}\left(\bar{\alpha}_{i t} Q E_{i t}+\bar{\beta}_{i t} w_{i t}\right) \leq C I(t) \quad t \in T$

where $\bar{\alpha}_{i t}, \bar{\beta}_{i t}$ are nondiscounted cost coefficients with regard to period $t$.

\subsection{Extension for contract models}

We modify problem P1 in order to consider contract models mentioned in a previous section. For this purpose we assume that we can purchase the raw materials from suppliers with any of the few types of contracts at each time $t$ (see Figure 4).

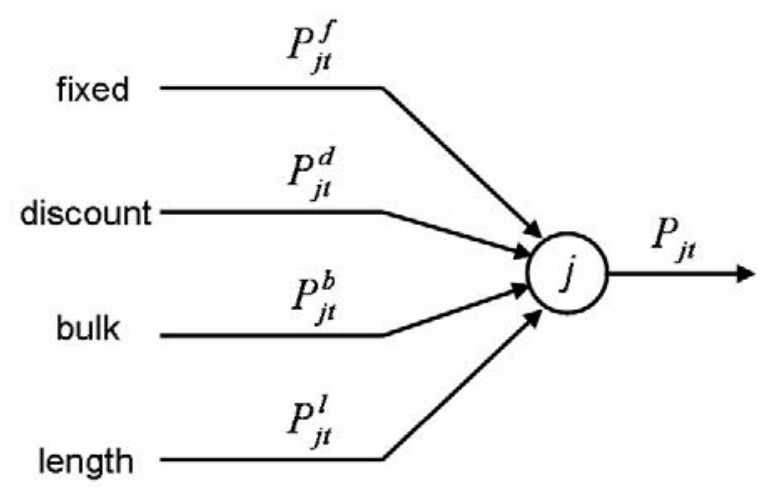

Figure 4. Purchase of raw materials with several contracts.

The objective function in P1 changes as follows,

$$
\begin{aligned}
\text { PROFIT } & =\sum_{j \in J} \sum_{t \in T} \psi_{j t} S_{j t}-\sum_{c \in C} \sum_{j \in J} \sum_{t \in T} \operatorname{COST}_{j t}^{c} \\
& -\sum_{i \in I} \sum_{j \in J M_{i}} \sum_{t \in T} \delta_{i t} W_{i j t}-\sum_{j \in J} \sum_{t \in T} \xi_{j t} V_{j t}-\sum_{j \in J} \sum_{t \in T} \theta_{j t} S F_{j t}
\end{aligned}
$$

whereas the corresponding one for $\mathrm{P} 2$ is:

$$
\begin{aligned}
N P V & =\sum_{j \in J} \sum_{t \in T} \psi_{j t} S_{j t}-\sum_{j \in J} \sum_{t \in T} \operatorname{COS} T_{j t}^{c} \\
& -\sum_{i \in I} \sum_{j \in J M_{i}} \sum_{t \in T} \delta_{i t} W_{i j t}-\sum_{i \in I} \sum_{t \in T}\left(\alpha_{i t} Q E_{i t}+\beta_{i t} w_{i t}\right)
\end{aligned}
$$

where $\operatorname{COST}_{j t}^{c}$ represents the cost of purchasing raw materials $j$ at time horizon $t$ under contract $c$.

Below we provide constraints to determine costs for each type of contract (see Figure 4).

$$
\begin{aligned}
& \operatorname{COST}_{j t}=\sum_{c \in C} \operatorname{COST}_{j t}^{c} \quad j \in J R, t \in T \\
& P_{j t}=P_{j t}^{f}+P_{j t}^{d}+P_{j t}^{b}+P_{j t}^{l} \quad j \in J R, t \in T
\end{aligned}
$$


$0 \leq P_{j t}^{c} \leq U y_{j t}^{c} \quad c \in C, j \in J R, t \in T$

$\sum_{c \in C} y_{j t}^{c} \leq 1 \quad j \in J R, t \in T$

$y_{j t}^{c} \in\{0,1\}, c \in C=\{f, d, b, l\}$

$\operatorname{COST}_{j t}$, the cost of purchasing raw material $j$ at time horizon $t$, is defined as the summation of $\operatorname{COST}_{j t}^{c}, c=f, d, b, l$, and $P_{j t}$, the amount of raw material $j$ purchased at time horizon $t$, is also defined as the summation of $P_{j t}^{c}$ in equations (30) and (31), respectively. The variables $P_{j t}^{c}$ have the upper and lower bounds in equation (32). We use the 0-1 binary variables that decide the contract to make. We assume that for each chemical $j$, the number of contracts that can be made at time $t$ must be equal or less than one at each time period $t$.

For the fixed price, the purchasing cost is simply equation (1).

$$
\operatorname{COST}_{j t}^{f}=\varphi_{j t}^{f} P_{j t}^{f} \quad j \in J R, t \in T
$$

For the disjunctions under contracts of the discount after certain amount, the bulk discount and the length contract (equations (2)-(6)), the convex hull formulation by Balas (1985) ${ }^{15}$ is used to convert these disjunctions into an MILP.

Firstly, we consider the disjunction in equation (3) under the discount after certain amount. To obtain the convex hull of equation (3), the continuous variables $P_{j t}^{d 1}$ are disaggregated, creating a variable for each disjunction in equation (36).

$$
\begin{aligned}
& \operatorname{COST}_{j t}^{d}=\varphi_{j t}^{d 1} P_{j t}^{d 1}+\varphi_{j t}^{d 2} P_{j t}^{d 2} \quad j \in J R, t \in T \\
& P_{j t}^{d}=P_{j t}^{d 1}+P_{j t}^{d 2} \quad j \in J R, t \in T \\
& P_{j t}^{d 1}=P_{j t}^{d 11}+P_{j t}^{d 12} \quad j \in J R, t \in T \\
& 0 \leq P_{j t}^{d 11} \leq y_{j t}^{d 1} \sigma_{j t}^{d} \quad j \in J R, t \in T \\
& P_{j t}^{d 12}=y_{j t}^{d 2} \sigma_{j t}^{d} \quad j \in J R, t \in T
\end{aligned}
$$


$0 \leq P_{j t}^{d 2} \leq y_{j t}^{d 2} U_{j t}^{d} \quad j \in J R, t \in T$

$y_{j t}^{d 1}+y_{j t}^{d 2}=y_{j t}^{d} \quad j \in J R, t \in T$

$y_{j t}^{d 1}, y_{j t}^{d 2} \in\{0,1\}$

Variable bounds and modification equations are now rewritten in terms of the disaggregated and binary variables (equations (37), (38) and (39)). In case the discount contract is selected, $y_{j t}^{d}$ is one, equation (40) enforces the requirement that only one binary variable be activated depending on the amount $\sigma_{j t}^{d}$ that is purchased.

Secondly, we consider the disjunction in equation (5) under the contract of bulk discount. Applying the convex hull to this equation yields the following constraints:

$$
\begin{aligned}
& \operatorname{COST}_{j t}^{b}=\varphi_{j t}^{b 1} P_{j t}^{b 1}+\varphi_{j t}^{b 2} P_{j t}^{b 2} \quad j \in J R, t \in T \\
& P_{j t}^{b}=P_{j t}^{b 1}+P_{j t}^{b 2} \quad j \in J R, t \in T \\
& 0 \leq P_{j t}^{b 1} \leq \sigma_{j t}^{b} y_{j t}^{b 1} \quad j \in J R, t \in T \\
& \sigma_{j t}^{b} y_{j t}^{b 2} \leq P_{j t}^{b 2} \leq U_{j t}^{b} y_{j t}^{b 2} \quad j \in J R, t \in T \\
& y_{j t}^{b 1}+y_{j t}^{b 2}=y_{j t}^{b} \quad j \in J R, t \in T \\
& y_{j t}^{b 1}, y_{j t}^{b 2} \in\{0,1\}
\end{aligned}
$$

In the fixed length contract, we convert the disjunctions in equation (6) into the MILP constraints as follows.

$$
\begin{aligned}
& \operatorname{COST}_{j t}^{l}=\sum_{p \in L C} \sum_{\tau \in T_{t}^{p}} \varphi_{j \tau}^{l p} P_{j \tau t}^{l p} \quad j \in J R, t \in T \\
& P_{j t}^{l}=\sum_{p \in L C} \sum_{\tau \in T_{t}^{p}} P_{j \tau t}^{l p} \quad j \in J R, t \in T \\
& \sigma_{j \tau}^{l p} y_{j \tau}^{l p} \leq P_{j \tau t}^{l p} \leq U_{j}^{l} y_{j \tau}^{l p} \quad j \in J R, t \in T_{\tau}^{p} \subset T, \tau \in T_{t}^{p} \subset T, p \in L C \\
& \sum_{p \in L C} y_{j \tau}^{l p} \leq y_{j \tau}^{l} \quad j \in J R, \tau \in T
\end{aligned}
$$


$y_{j \tau}^{l p} \in\{0,1\}, L C=\{1,2,3\}$

In the above equations $L C$ is a set of contract lengths. $\tau$ is the time period at which the contract is made and $t$ is the time period in which the raw material is purchased. $P_{j \pi t}^{l p}$ represents the amount of raw materials $j$ purchased in time period $t$ under length contract $p$ made at time $\tau(\tau \leq t)$. Here $T_{t}^{p}$ is a set of time periods $\tau$ at which the contract is made in order to purchase the raw material in time period $t$ for length contract $p$, while $T_{\tau}^{p}$ is a set of time periods $t$ in which the raw material is purchased with length contract $p$ made at time period $\tau$. The $0-1$ variables $y_{j \tau}^{l p}$ represent the decision of length contract $p$ with raw material $j$ at time $\tau$.

In the same way as we can purchase raw materials from suppliers with any of the types of contract at each time $t$, customers can buy products from our company through different types of contracts at each time $t$ (see Figure 5).

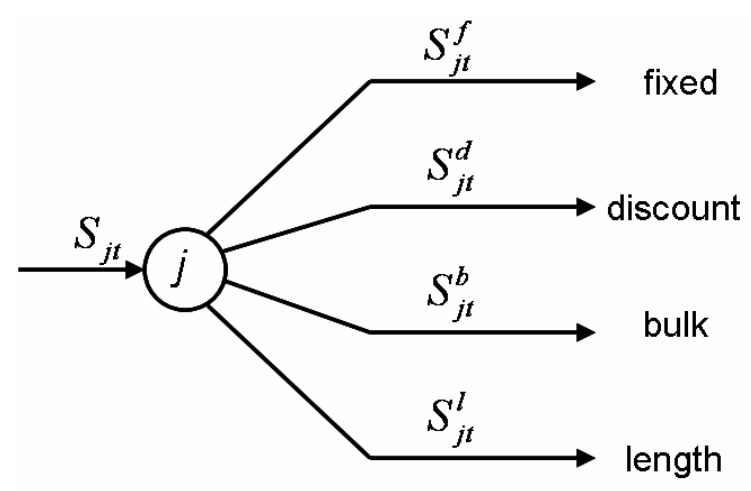

Figure 5. Sale of products by means of several types of contracts.

The new objective function for P1 is as follows:

$$
\begin{aligned}
\text { PROFIT } & =\sum_{c \in C P} \sum_{j \in J} \sum_{t \in T} R E V_{j t}^{c}-\sum_{c \in C R} \sum_{j \in J} \sum_{t \in T} \operatorname{COST}_{j t}^{c} \\
& -\sum_{i \in I} \sum_{j \in J M_{i}} \sum_{t \in T} \delta_{i t} W_{i j t}-\sum_{j \in J} \sum_{t \in T} \xi_{j t} V_{j t}-\sum_{j \in J} \sum_{t \in T} \theta_{j t} S F_{j t}
\end{aligned}
$$

and for $\mathrm{P} 2$ is:

$$
\begin{aligned}
N P V & =\sum_{j \in J} \sum_{t \in T} R E V_{j t}^{c}-\sum_{j \in J} \sum_{t \in T} C O S T_{j t}^{c} \\
& -\sum_{i \in I} \sum_{j \in J M_{i}} \sum_{t \in T} \delta_{i t} W_{i j t}-\sum_{i \in I} \sum_{t \in T}\left(\alpha_{i t} Q E_{i t}+\beta_{i t} w_{i t}\right)
\end{aligned}
$$


where $R E V_{j t}^{c}$ represents the revenues for selling product $j$ at time $t$ under contract type $c$. Below we provide constraints to determine revenues for each type of contract.

$$
\begin{aligned}
& R E V_{j t}=\sum_{c \in C P} R E V_{j t}^{c} \quad j \in J P, t \in T \\
& S_{j t}=S_{j t}^{f}+S_{j t}^{d}+S_{j t}^{b}+S_{j t}^{l} \quad j \in J P, t \in T \\
& 0 \leq S_{j t}^{c} \leq U z_{j t}^{c} \quad c \in C P, j \in J P, t \in T \\
& \sum_{c \in C P} z_{j t}^{c} \leq 1 \quad j \in J P, t \in T \\
& z_{j t}^{c} \in\{0 ; 1\}, c \in C=\{f ; d ; b ; l\}
\end{aligned}
$$

For the fixed price, the revenues are simply given by:

$$
R E V_{j t}^{f}=\psi_{j t}^{f} S_{j t}^{f} \quad j \in J P, t \in T
$$

For the disjunctions under contracts of the discount after certain amount, the bulk discount and the length contract, the convex hull is also used to obtain the corresponding MILP. To obtain the convex hull of equation (9), the continuous variables $S_{j t}^{d 1}$ are disaggregated to give:

$$
\begin{aligned}
& R E V_{j t}^{d}=\psi_{j t}^{d 1} S_{j t}^{d 1}+\psi_{j t}^{d 2} S_{j t}^{d 2} \quad j \in J P, t \in T \\
& S_{j t}^{d}=S_{j t}^{d 1}+S_{j t}^{d 2} \quad j \in J P, t \in T \\
& S_{j t}^{d 1}=S_{j t}^{d 11}+S_{j t}^{d 12} \quad j \in J P, t \in T \\
& 0 \leq S_{j t}^{d 11} \leq z_{j t}^{d 1} \rho_{j t}^{d} \quad j \in J P, t \in T \\
& S_{j t}^{d 12}=z_{j t}^{d 2} \rho_{j t}^{d} \quad j \in J P, t \in T \\
& 0 \leq S_{j t}^{d 2} \leq z_{j t}^{d 2} U_{j t}^{d} \quad j \in J P, t \in T \\
& Z_{j t}^{d 1}+z_{j t}^{d 2}=z_{j t}^{d} \quad j \in J P, t \in T \\
& Z_{j t}^{d}, Z_{j t}^{d 1}, Z_{j t}^{d 2} \in\{0 ; 1\}
\end{aligned}
$$


Secondly, we consider the disjunction in equation (11) under the contract of bulk discount. The convex hull is obtained with:

$$
\begin{aligned}
& R E V_{j t}^{b}=\psi_{j t}^{b 1} S_{j t}^{b 1}+\psi_{j t}^{b 2} S_{j t}^{b 2} \quad j \in J P, t \in T \\
& S_{j t}^{b}=S_{j t}^{b 1}+S_{j t}^{b 2} \quad j \in J P, t \in T \\
& 0 \leq S_{j t}^{b 1} \leq \rho_{j t}^{b} z_{j t}^{b 1} \quad j \in J P, t \in T \\
& \rho_{j t}^{b} z_{j t}^{b 2} \leq S_{j t}^{b 2} \leq U_{j t}^{b} z_{j t}^{b 2} \quad j \in J P, t \in T \\
& z_{j t}^{b 1}+z_{j t}^{b 2}=z_{j t}^{b} \quad j \in J P, t \in T \\
& z_{j t}^{b 1}, z_{j t}^{b 2} \in\{0 ; 1\}
\end{aligned}
$$

In the fixed length contract, we convert the disjunctions in equation (12) into the MILP constraints as follows.

$$
\begin{aligned}
& R E V_{j t}^{l}=\sum_{p \in L C} \sum_{\tau \in T_{t}^{p}} \psi_{j \tau}^{l p} S_{j \hbar t}^{l p} \quad j \in J P, t \in T \\
& S_{j t}^{l}=\sum_{p \in L C} \sum_{\tau \in T_{t}^{p}} S_{j \tau t}^{l p} \quad j \in J P, t \in T \\
& \rho_{j \tau}^{l p} Z_{j \tau}^{l p} \leq S_{j \tau t}^{l p} \leq U_{j}^{l} z_{j \tau}^{l p} \quad j \in J P, t \in T_{\tau}^{p} \subset T, \tau \in T_{t}^{p} \subset T, p \in L C \\
& \sum_{p \in L C} z_{j \tau}^{l p} \leq z_{j \tau}^{l} \quad j \in J P, \tau \in T \\
& z_{j \tau}^{l p} \in\{0 ; 1\}, L C=\{1 ; 2 ; 3\}
\end{aligned}
$$

Then, the extension of model P1 for contracts with customers and suppliers are given by equations (51), (1), (7), (14)-(22), (31)-(50) and (53)-(72). For the long-term case, the extension of model P2 is given by equations (52), (1), (7), (14)-(17), (31)-(50) and (53)-(72).

\section{Example 1.}

\subsection{Description}


In this section, the example problem in Figure 6 is solved to illustrate the performance of the models in three cases: (1) short-term planning of the production of each process, the inventory of each product and purchase of raw materials with no contract, (2) short-term planning with contracts only with the suppliers, (3) short-term planning with contracts with both the suppliers and the customers. All the cases (1, 2 and 3) are extensions of model P1.

The system is a three-process network that manufactures products D and E from raw materials A, B and C. We use a 6-month planning horizon.

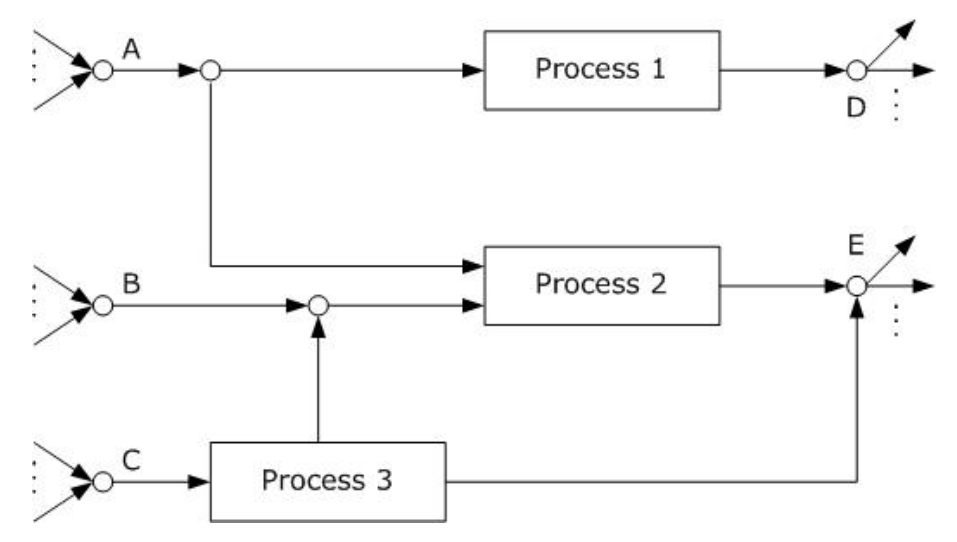

Figure 6. Process network for example.

For the purchase of the raw materials and the sale of the products, we consider the four contracts described previously in the paper. The prices of raw materials and products in each contract are given in Tables 1, 7-9 and 11-13. In Table 1, the market prices of raw materials varying with time period are considered as the price of the fixed price contract.

We assume that for process 3, 83\% of converted $\mathrm{C}$ makes $\mathrm{E}$ and the remaining $17 \%$ makes $\mathrm{B}$, and that reactants $\mathrm{A}$ and $\mathrm{B}$ are fed to process 2 in a 10:1 ratio ${ }^{16}$. Existing capacities of each process are 27, 30, and 25 tons, respectively. In this example, the inventories and penalties are considered only for productions. The upper bound for product demand varies with time period. The rest of data for this example are shown in Tables 2-6, 10 and 14. 
Table 1. Prices of raw materials and products $\left(\varphi_{j t}, \psi_{j t}\right)[100 \$ /$ ton $]$ at time period $t$

\begin{tabular}{ccccccc}
\hline & \multicolumn{7}{c}{ Time period } \\
\cline { 2 - 7 } Chemical & 1 & 2 & 3 & 4 & 5 & 6 \\
\hline A & 2.20 & 2.40 & 2.40 & 2.30 & 2.20 & 2.20 \\
B & 1.90 & 2.40 & 2.40 & 2.20 & 2.10 & 2.10 \\
C & 5.20 & 5.70 & 5.50 & 5.40 & 5.70 & 5.70 \\
D & 22.1 & 23.9 & 24.4 & 22.7 & 27.9 & 23.6 \\
E & 20.5 & 21.5 & 24.5 & 21.2 & 22.8 & 24.9
\end{tabular}

Table 2. Production capacity $\left(Q_{i t}\right)[$ kton] of each process

\begin{tabular}{cc}
\hline Process & Existing capacity \\
\hline P1 & 27 \\
P2 & 30 \\
P3 & 25
\end{tabular}

Table 3. Operating cost coefficient $\left(\delta_{i t}\right)[100 \$ /$ ton $]$ at time period $t$

\begin{tabular}{ccccccc}
\hline & \multicolumn{7}{c}{ Time period } \\
\cline { 2 - 7 } Process & 1 & 2 & 3 & 4 & 5 & 6 \\
\hline P1 & 0.6 & 0.7 & 0.6 & 0.6 & 0.7 & 0.7 \\
P2 & 0.5 & 0.5 & 0.5 & 0.4 & 0.4 & 0.5 \\
P3 & 0.6 & 0.6 & 0.5 & 0.6 & 0.6 & 0.5
\end{tabular}

Table 4. Upper bound for raw material availability $\left(a_{j t}^{L}, a_{j t}^{U}\right)[\mathrm{kton}]$ at time period $t$

\begin{tabular}{cccccccc}
\hline & & \multicolumn{7}{c}{ Time period } \\
\cline { 3 - 8 } Chemical & & 1 & 2 & 3 & 4 & 5 & 6 \\
\hline \multirow{2}{*}{ A } & UB & 100 & 100 & 100 & 100 & 100 & 100 \\
& LB & 0 & 0 & 0 & 0 & 0 & 0 \\
B & UB & 30 & 30 & 30 & 30 & 30 & 30 \\
& LB & 0 & 0 & 0 & 0 & 0 & 0 \\
C & UB & 100 & 100 & 100 & 100 & 100 & 100 \\
& LB & 0 & 0 & 0 & 0 & 0 & 0
\end{tabular}


Table 5. Upper and lower bounds for product demand $\left(d_{j t}^{L}, d_{j t}^{U}\right)[\mathrm{kton}]$ at time period $t$

\begin{tabular}{cccccccc}
\hline \multirow{2}{*}{ Chemical } & & \multicolumn{7}{c}{ Time period } \\
\cline { 3 - 8 } D & UB & 20 & 25 & 3 & 4 & 5 & 6 \\
\hline \multirow{2}{*}{ E } & LB & 5 & 5 & 5 & 5 & 5 & 5 \\
& UB & 51 & 50 & 53 & 60 & 59 & 50 \\
& LB & 5 & 5 & 5 & 5 & 5 & 5
\end{tabular}

Table 6. Shortfall penalty $\left(\theta_{j t}\right)[100 \$ / t o n]$ and upper bound $\left(S F_{j t}^{U}\right)[\mathrm{kton}]$, and inventory cost $\left(\xi_{j t}\right)$ [100\$/ton] and upper bound $\left(V_{j t}^{U}\right)[\mathrm{kton}]$ for each product

\begin{tabular}{ccc}
\hline & \multicolumn{2}{c}{ Production } \\
\cline { 2 - 3 }$(t=1, \ldots, 6)$ & $\mathrm{D}$ & $\mathrm{E}$ \\
\hline Shortf. & 2 & 2 \\
penalty & 10 & 10 \\
Shortf. UB & 10 & 2 \\
Invent. cost & 2 & 30 \\
Invent. UB & 30 &
\end{tabular}

Table 7. Prices of the raw materials $\left(\varphi_{j t}^{d 1}, \varphi_{j t}^{d 2}\right)[100 \$ /$ ton $]$ with the discount contract at time $t$

\begin{tabular}{cccccccc}
\hline & & \multicolumn{7}{c}{ Time period } \\
\cline { 2 - 8 } Chemical & Scheme & 1 & 2 & 3 & 4 & 5 & 6 \\
\hline \multirow{2}{*}{ A } & 1 & 2.25 & 2.25 & 2.25 & 2.25 & 2.25 & 2.25 \\
& 2 & 2.15 & 2.15 & 2.15 & 2.15 & 2.15 & 2.15 \\
B & 1 & 2.35 & 2.35 & 2.35 & 2.35 & 2.35 & 2.35 \\
& 2 & 2.10 & 2.10 & 2.10 & 2.10 & 2.10 & 2.10 \\
C & 1 & 5.50 & 5.50 & 5.50 & 5.50 & 5.50 & 5.50 \\
& 2 & 5.30 & 5.30 & 5.30 & 5.30 & 5.30 & 5.30
\end{tabular}

Table 8. Prices of the raw materials $\left(\varphi_{j t}^{b 1}, \varphi_{j t}^{b 2}\right)[100 \$ /$ ton] with the bulk contract at time $t$

\begin{tabular}{cccccccc}
\hline & & \multicolumn{7}{c}{ Time period } \\
\cline { 3 - 8 } Chemical & Scheme & 1 & 2 & 3 & 4 & 5 & 6 \\
\hline \multirow{2}{*}{ A } & 1 & 2.30 & 2.30 & 2.30 & 2.30 & 2.30 & 2.30 \\
& 2 & 2.10 & 2.10 & 2.10 & 2.10 & 2.10 & 2.10 \\
B & 1 & 2.35 & 2.35 & 2.35 & 2.35 & 2.35 & 2.35 \\
& 2 & 2.00 & 2.00 & 2.00 & 2.00 & 2.00 & 2.00 \\
C & 1 & 5.50 & 5.50 & 5.50 & 5.50 & 5.50 & 5.50 \\
& 2 & 5.25 & 5.25 & 5.25 & 5.25 & 5.25 & 5.25
\end{tabular}


Table 9. Prices of the raw materials $\left(\varphi_{j \tau}^{l p}\right)[100 \$ /$ ton $]$ with the length contract at time period $t$

\begin{tabular}{cccccccc}
\hline & & \multicolumn{7}{c}{ Time period } \\
\cline { 3 - 8 } Chemical & Length & 1 & 2 & 3 & 4 & 5 & 6 \\
\hline \multirow{2}{*}{ A } & 1 & 2.25 & 2.25 & 2.25 & 2.25 & 2.25 & 2.25 \\
& 2 & 2.20 & 2.20 & 2.20 & 2.20 & 2.20 & 2.20 \\
& 3 & 2.15 & 2.15 & 2.15 & 2.15 & 2.15 & 2.15 \\
B & 1 & 2.35 & 2.35 & 2.35 & 2.35 & 2.35 & 2.35 \\
& 2 & 2.25 & 2.25 & 2.25 & 2.25 & 2.25 & 2.25 \\
& 3 & 2.15 & 2.15 & 2.15 & 2.15 & 2.15 & 2.15 \\
C & 1 & 5.50 & 5.50 & 5.50 & 5.50 & 5.50 & 5.50 \\
& 2 & 5.40 & 5.40 & 5.40 & 5.40 & 5.40 & 5.40 \\
& 3 & 5.30 & 5.30 & 5.30 & 5.30 & 5.30 & 5.30
\end{tabular}

Table 10. Minimum amounts $\left(\sigma_{j t}^{c}\right)$ [kton] of raw materials in each contract

\begin{tabular}{ccccccc}
\hline $\left.\begin{array}{c}\text { Chemical } \\
(t=1, \ldots, 6\end{array}\right)$ & Fixed & Discount & Bulk & \multicolumn{3}{c}{ Length } \\
\cline { 5 - 7 } A & 0 & 63 & 64 & 0 & 63 & 66 \\
B & 0 & 4 & 5 & 0 & 3 & 4 \\
C & 0 & 22 & 24 & 0 & 22 & 24
\end{tabular}

Table 11. Prices of the products $\left(\psi_{j t}^{d 1}, \psi_{j t}^{d 2}\right)[100 \$ /$ ton] with the discount contract at time $t$

\begin{tabular}{cccccccc}
\hline & & \multicolumn{7}{c}{ Time period } \\
\cline { 3 - 8 } Chemical & Scheme & 1 & 2 & 3 & 4 & 5 & 6 \\
\hline \multirow{2}{*}{ D } & 1 & 24.10 & 24.10 & 24.10 & 24.10 & 24.10 & 24.10 \\
& 2 & 22.00 & 22.00 & 22.00 & 22.00 & 22.00 & 22.00 \\
& 1 & 22.50 & 22.50 & 22.50 & 22.50 & 22.50 & 22.50 \\
E & 2 & 20.40 & 20.40 & 20.40 & 20.40 & 20.40 & 20.40
\end{tabular}

Table 12. Prices of the products $\left(\psi_{j t}^{b 1}, \psi_{j t}^{b 2}\right)[100 \$ /$ ton $]$ with the bulk contract at time $t$

\begin{tabular}{cccccccc}
\hline & & \multicolumn{7}{c}{ Time period } \\
\cline { 3 - 8 } Chemical & Scheme & 1 & 2 & 3 & 4 & 5 & 6 \\
\hline \multirow{2}{*}{ D } & 1 & 24.10 & 24.10 & 24.10 & 24.10 & 24.10 & 24.10 \\
& 2 & 21.50 & 21.50 & 21.50 & 21.50 & 21.50 & 21.50 \\
\multirow{2}{*}{ E } & 1 & 22.50 & 22.50 & 22.50 & 22.50 & 22.50 & 22.50 \\
& 2 & 20.00 & 20.00 & 20.00 & 20.00 & 20.00 & 20.00
\end{tabular}


Table 13. Prices of the products $\left(\psi_{j \tau}^{l p}\right)[100 \$ /$ ton] with the length contract at time period $t$

\begin{tabular}{cccccccc}
\hline & & \multicolumn{6}{c}{ Time period } \\
\cline { 3 - 7 } Chemical & Length & 1 & 2 & 3 & 4 & 5 & 6 \\
\hline \multirow{2}{*}{ D } & 1 & 24.10 & 24.10 & 24.10 & 24.10 & 24.10 & 24.10 \\
& 2 & 23.05 & 23.05 & 23.05 & 23.05 & 23.05 & 23.05 \\
& 3 & 22.00 & 22.00 & 22.00 & 22.00 & 22.00 & 22.00 \\
\multirow{2}{*}{ E } & 1 & 22.50 & 22.50 & 22.50 & 22.50 & 22.50 & 22.50 \\
& 2 & 21.45 & 21.45 & 21.45 & 21.45 & 21.45 & 21.45 \\
& 3 & 20.40 & 20.40 & 20.40 & 20.40 & 20.40 & 20.40
\end{tabular}

Table 14. Minimum amounts $\left(\rho_{j t}^{c}\right)$ [kton] of raw materials in each contract

\begin{tabular}{ccccccc}
\hline $\begin{array}{c}\text { Chemical } \\
(t=1, \ldots, 6)\end{array}$ & Fixed & Discount & Bulk & \multicolumn{3}{c}{ Length } \\
\cline { 5 - 7 } & & & & 1 & 2 & 3 \\
\hline $\mathrm{D}$ & 0 & 10 & 10 & 0 & 10 & 20 \\
$\mathrm{E}$ & 0 & 40 & 40 & 0 & 40 & 50
\end{tabular}

\subsection{Results}

The extended MILP problem P1 is modeled using the GAMS modeling language and solved using the CPLEX solver on a 3.20GHz Pentium PC, with 512Mbyte of RAM. The computational results are shown in Table 15.

Table 15. Computational statistics for the first example.

\begin{tabular}{cccccc}
\hline Case & $\begin{array}{c}0-1 \\
\text { variables }\end{array}$ & $\begin{array}{c}\text { Continuous } \\
\text { variables }\end{array}$ & Constraints & $\begin{array}{c}\text { CPU } \\
\text { time }[\mathrm{s}]\end{array}$ & $\begin{array}{c}\text { Solution } \\
{[105 \$]}\end{array}$ \\
\hline 1 & 0 & 104 & 159 & 0 & $7,848.91$ \\
2 & 198 & 560 & 626 & 8.73 & $7,896.83$ \\
3 & 336 & 870 & 938 & 214.44 & $8,193.16$
\end{tabular}

The increase of CPU time in the last case is likely due to the existence of many choices of contract with the customers yielding very similar profit values. Therefore, the exploration of the branch and bound tree for this case is very large. Cases 1 and 2 can be compared between them in order to see the effect of the contracts consideration in the model. Comparisons with case 3, however, are not possible since different data are used to express customer demand. 
Figure 7 shows which contracts are selected to purchase the raw materials in case 2, and Figures 8 and 9 do the same for suppliers' and customers' contracts in case 3. In both cases, 2 and 3, raw material B is not purchased. As it can be seen, decisions for raw material contracts are exactly the same in both cases considered. In the case of customers' contracts, results show, as it can be expected, that those choices with higher price (according to the prices used) are the preferred ones, i.e. fixed contracts and length contracts with only one month duration.

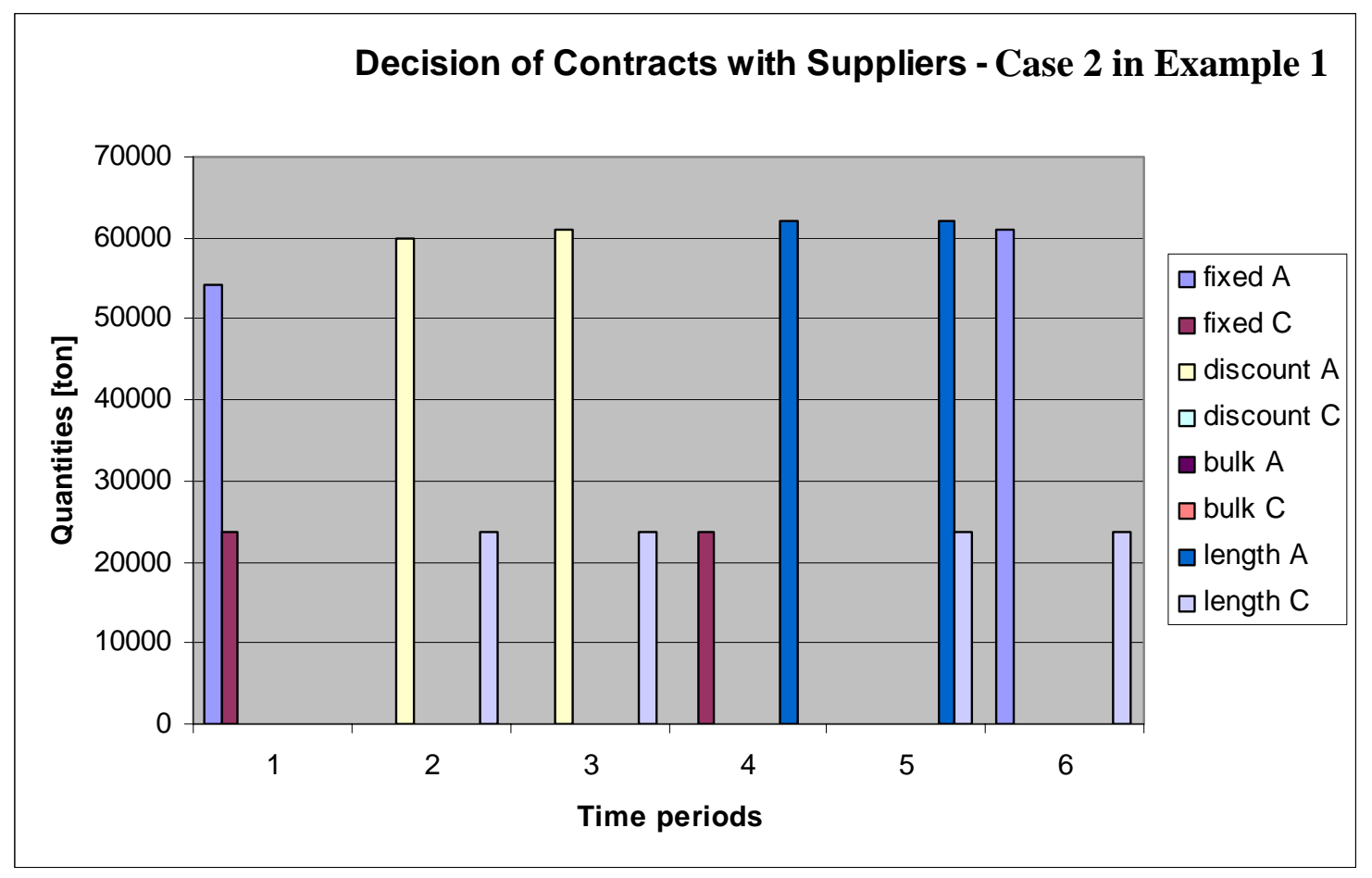

Figure 7. Decision of contracts for suppliers in case 2 in Example 1. 


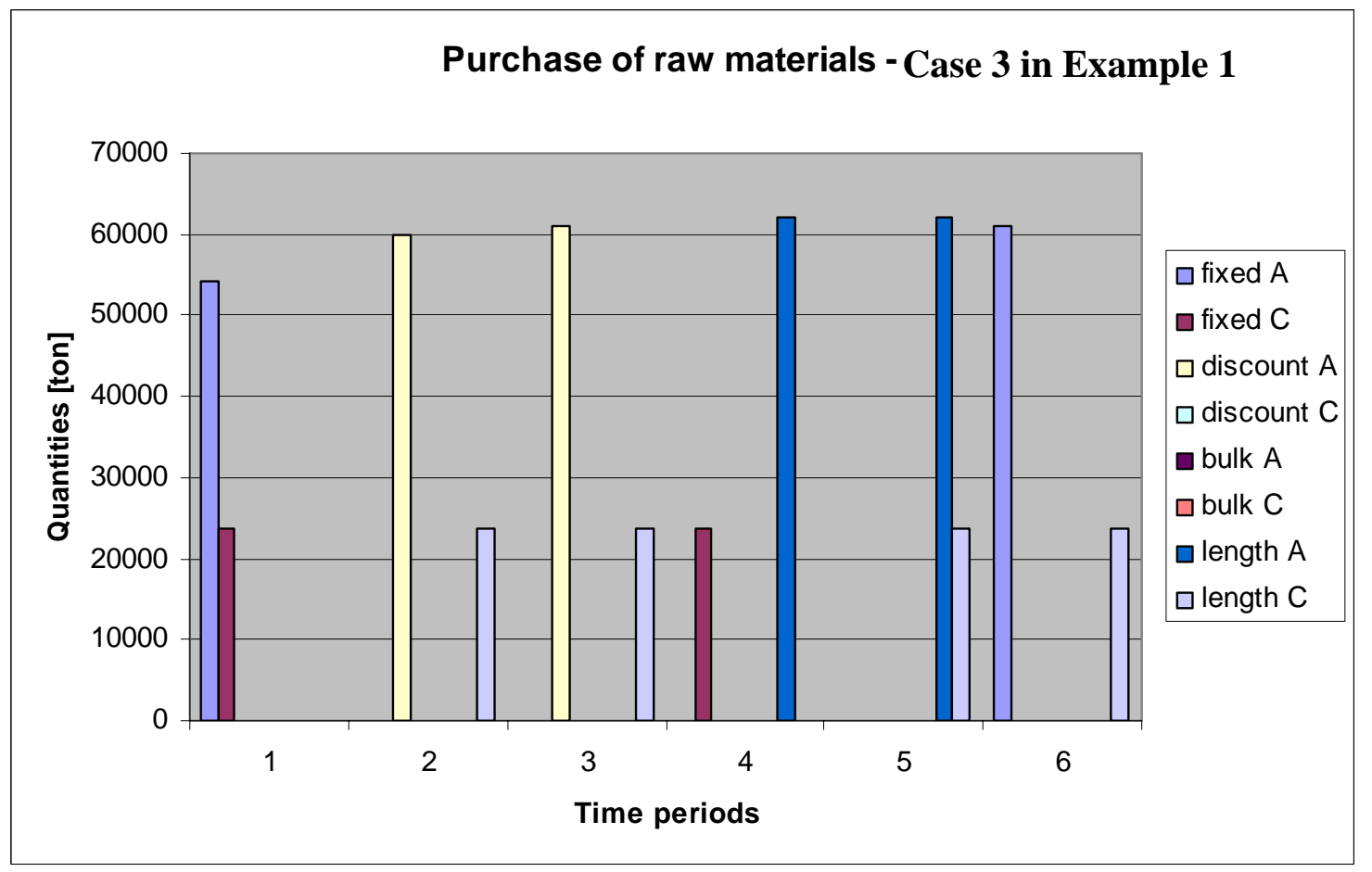

Figure 8. Decision of contracts for suppliers in case 3 in Example 1.

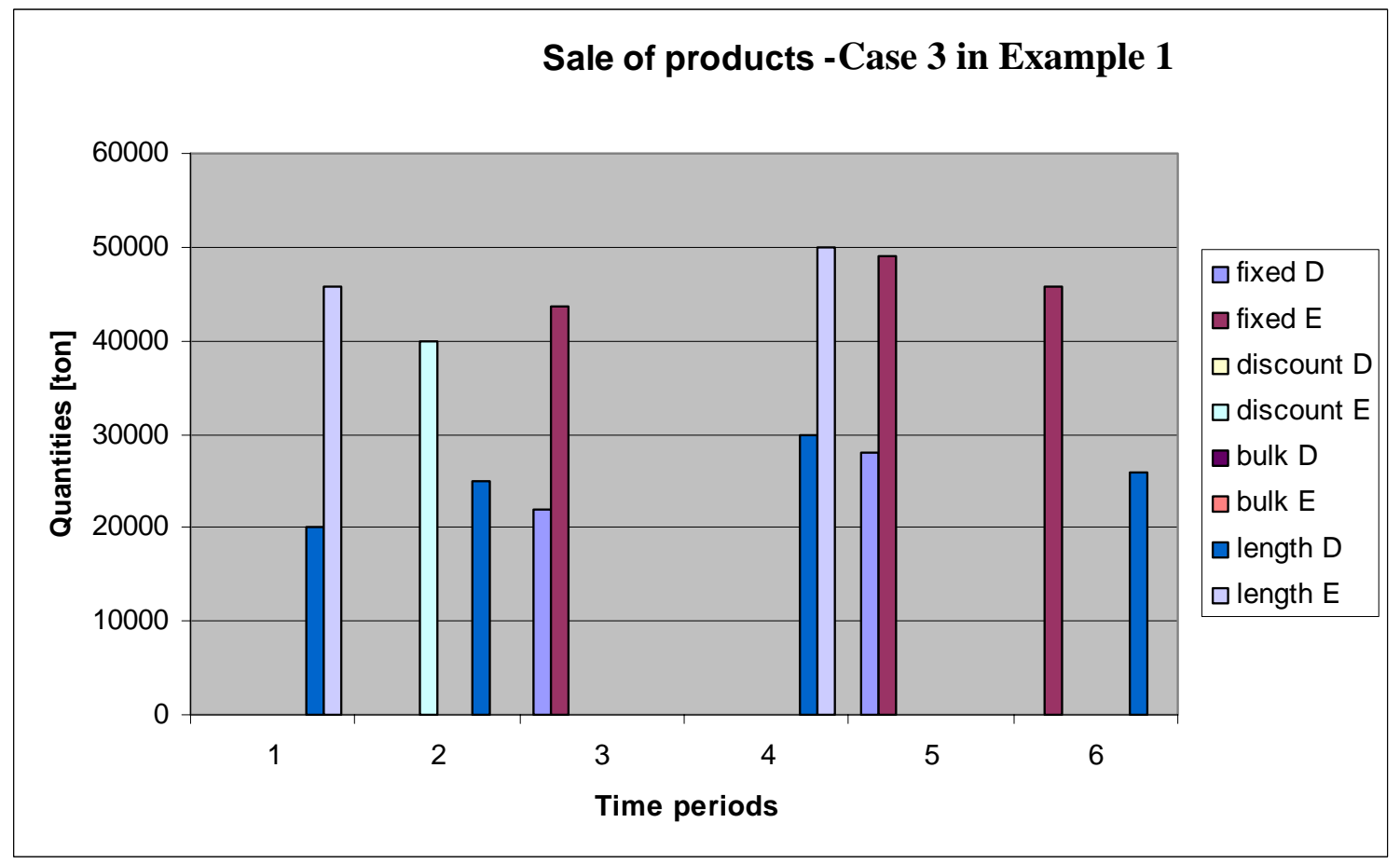

Figure 9. Decision of contracts for customers in case 3 in Example 1. 
Figure 10 shows a comparison between cases 1 and 2. It can be seen that the slightly larger profit in the case of using contracts is due to a slightly smaller purchase cost in the case of using contracts whereas the other costs and revenues remain unchanged. That behavior is typical of a case in which the system is working at full capacity. This can be seen in Figure 11 that shows that demand satisfaction does not improve significantly with the choice of contracts.

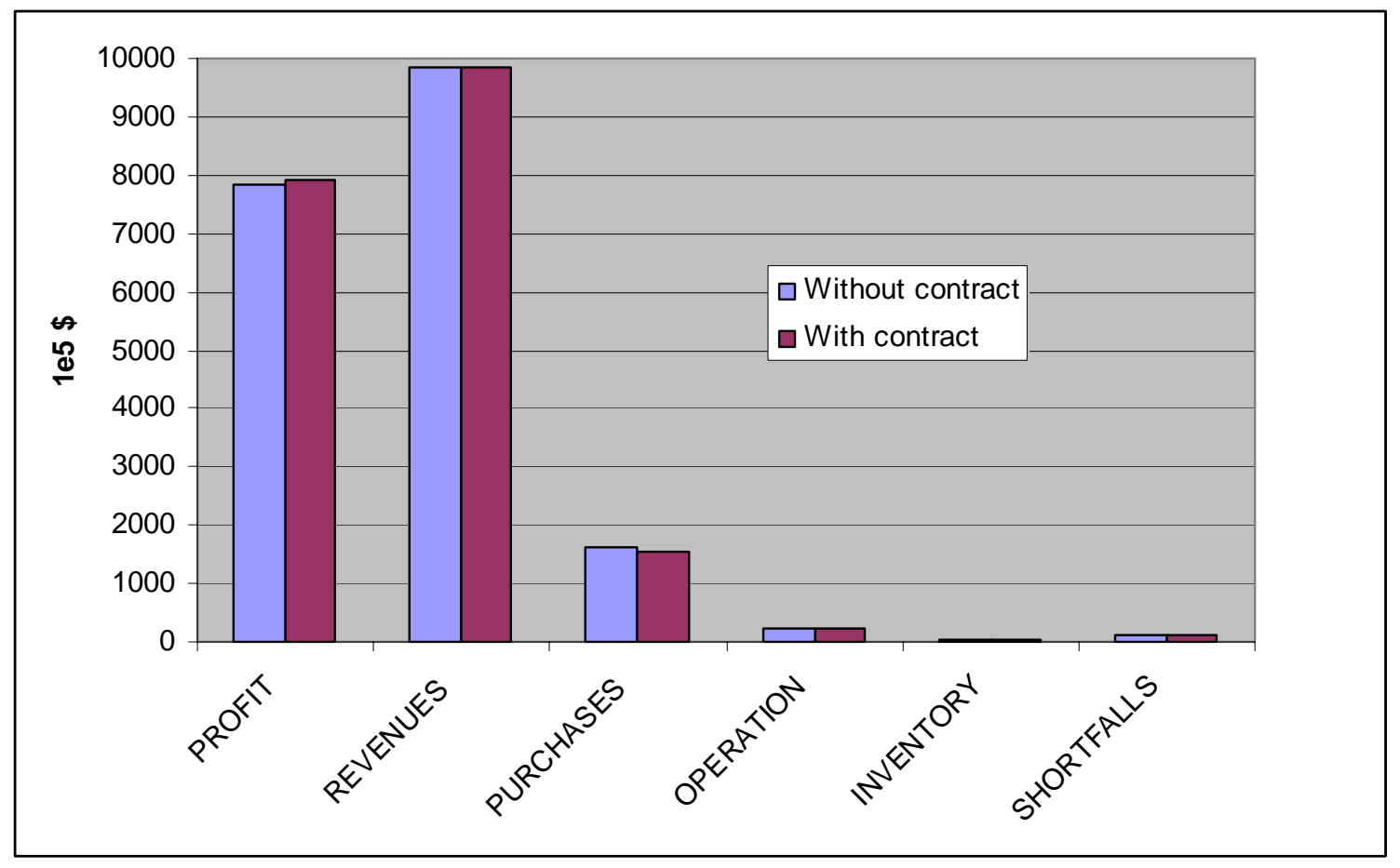

Figure 10. Comparison in revenues and costs in cases 1 and 2. 


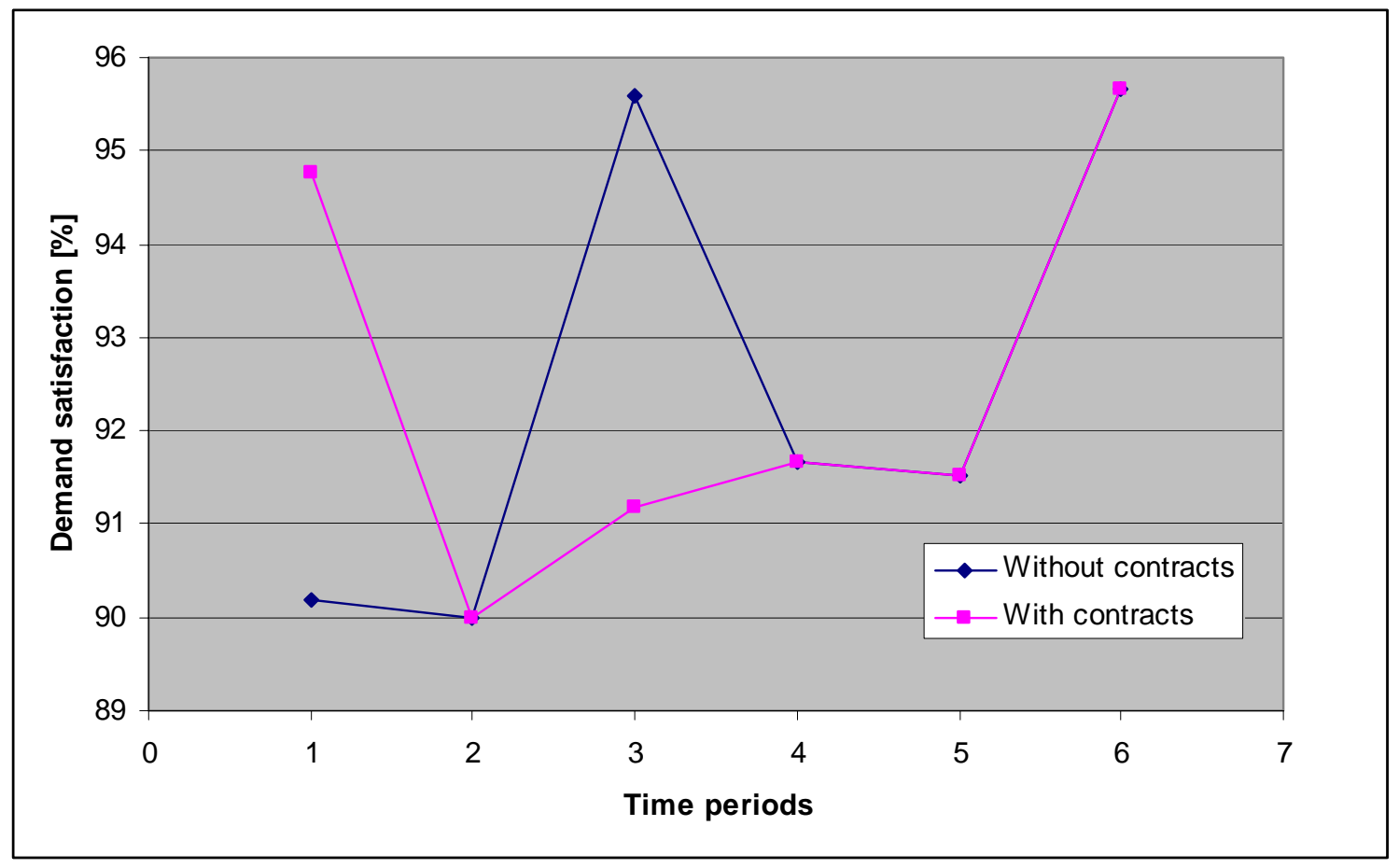

Figure 11. Demand satisfaction per time period in cases 1 and 2.

\section{Remarks on contracts with customers}

From the customer side in a supply chain, the fact of making contracts is tightly related to the way in which the customer demand is expressed in the model. The case of a fixed contract is the case where the demand in a given time interval is expressed as a fixed quantity between lower and upper bounds. On the other hand, discount and bulk contracts are possible when the demand is expressed as a certain amount at a relatively high price or a larger quantity if a lower price is allowed. While bulk contracts are more realistic because they promote higher production levels, length contracts are not profitable if one assumes deterministic demands.

In the case of customers' length contracts, benefits only derive if demands are uncertain as they have the effect of reducing the uncertainty. This is an important difference from the case of suppliers' contracts, in which there are direct benefits for the company due to the economies of scale. Therefore, the equations considered for customer contracts are only useful in the context of stochastic programming approaches to address uncertainties in demand in real world applications 


\section{Example 2.}

\subsection{Description}

This example includes four different case studies all based on a petrochemical network that involves 38

processes and 28 chemicals. (Sahinidis et al. $(1989)^{17}$ ). The process network considered in this study is shown in detail in Figure 12 and more schematically in Figure 13. 


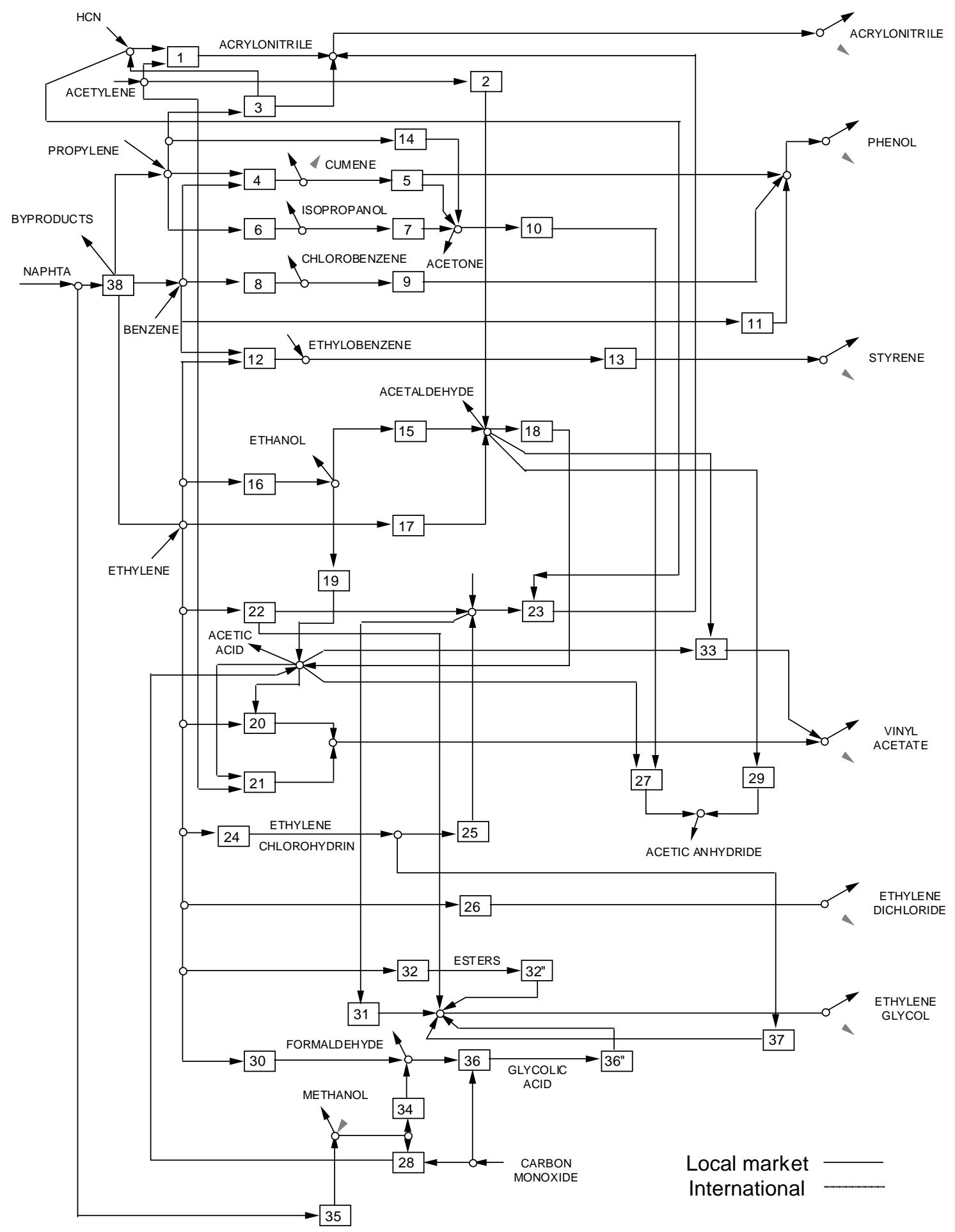

Figure 12. Process network diagram showing the direction of material flows in Example 2. 


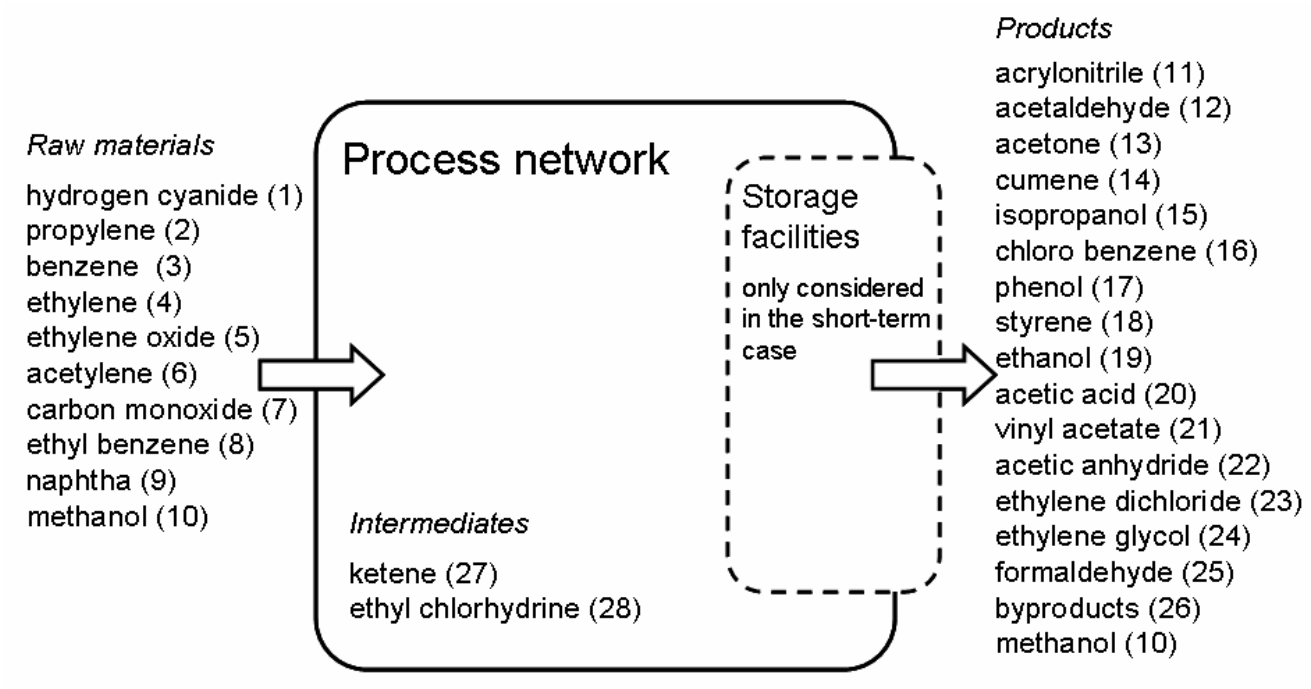

Figure 13. Inputs and outputs of the process network studied in Example 2.

As can be seen in Figure 13, the process networks use as inputs the following chemicals: hydrogen cyanide, propylene, benzene, ethylene, ethylene oxide, acetylene, carbon monoxide, ethyl benzene, naphtha and methanol. The outputs are: acrylonitrile, acetaldehyde, acetone, cumene, isopropanol, chloro benzene, phenol, styrene, ethanol, acetic acid, vinyl acetate, acetic anhydride, ethylene dichloride, ethylene glycol, formaldehyde, byproducts and also methanol. All these products are assumed to be stored before selling; therefore, in the short-term it is necessary to include the inventories. Finally, there are two intermediate products: ketene and ethylene chlorohydrin.

The products manufactured can be sold to the local and to the international market and the raw materials can also be bought from the local or the international market as shown in figure 13 . This introduces a new subscript $k$ in $\psi_{j t k}, S_{j t k}, \varphi_{j t k}$ and $P_{j t k} . k=1$ accounts for local market and $k=2$ for international market.

The four case studies are the following:

Case 1. In this case, the short-term problem is posed along a horizon time divided into 10 months. There are no investment considerations and the purchase of raw materials is performed directly, without contracts. 
Case 2. This case is a modification of case (1) but with the possibility of signing contracts for the acquisition of three of the main raw materials: naphtha (Naph), ethylene (Ethy) and acetylene (Acet), in the local market.

Case 3. In this case, the problem is a long-term one, where decisions on capacity expansions are included. The time horizon covers 4 time periods of one year each. Inventory considerations are not taken into account and the purchase of raw materials is performed without contracts.

Case 4: It is also a capacity expansion problem but with the additional feature of allowing the choice of contracts for naphtha, ethylene and acetylene in the local market.

For the contracts, we consider those types described previously in the paper. Data for these problems are not presented given their great length, but they are available from the authors.

\subsection{Results}

The LP and MILP resulting problems are modeled using the GAMS modeling language and solved using the CPLEX solver on a 3.20GHz Pentium PC, with 512Mbyte of RAM. The computational results are shown in Table 16.

Table 16. Computational statistics for the second example.

\begin{tabular}{ccccccc}
\hline Case & $\begin{array}{c}0-1 \\
\text { variables }\end{array}$ & $\begin{array}{c}\text { Continuous } \\
\text { variables }\end{array}$ & Constraints & $\begin{array}{c}\text { CPU } \\
\text { time [s] }\end{array}$ & $\begin{array}{c}\text { Time } \\
\text { periods }\end{array}$ & $\begin{array}{c}\text { Solution } \\
{[105 \$]}\end{array}$ \\
\hline 1 & 0 & 12,606 & 13,416 & 0.18 & 10 & $18,085.95$ \\
2 & 6,160 & 40,606 & 46,002 & 0.95 & 10 & $22,073.06$ \\
3 & 152 & 5,161 & 5,269 & 1.20 & 4 & $5,935.7$ \\
4 & 2,616 & 12,329 & 14,017 & 0.89 & 4 & $6,897.43$
\end{tabular}

For the short-term planning problem, Figure 14 shows which contracts are selected for purchasing raw materials in case 2, and Figure 15 shows comparatively the amounts in cases 1 and 2 . The biggest difference is the increase in the purchase of naphtha (Naph) in case 2. 


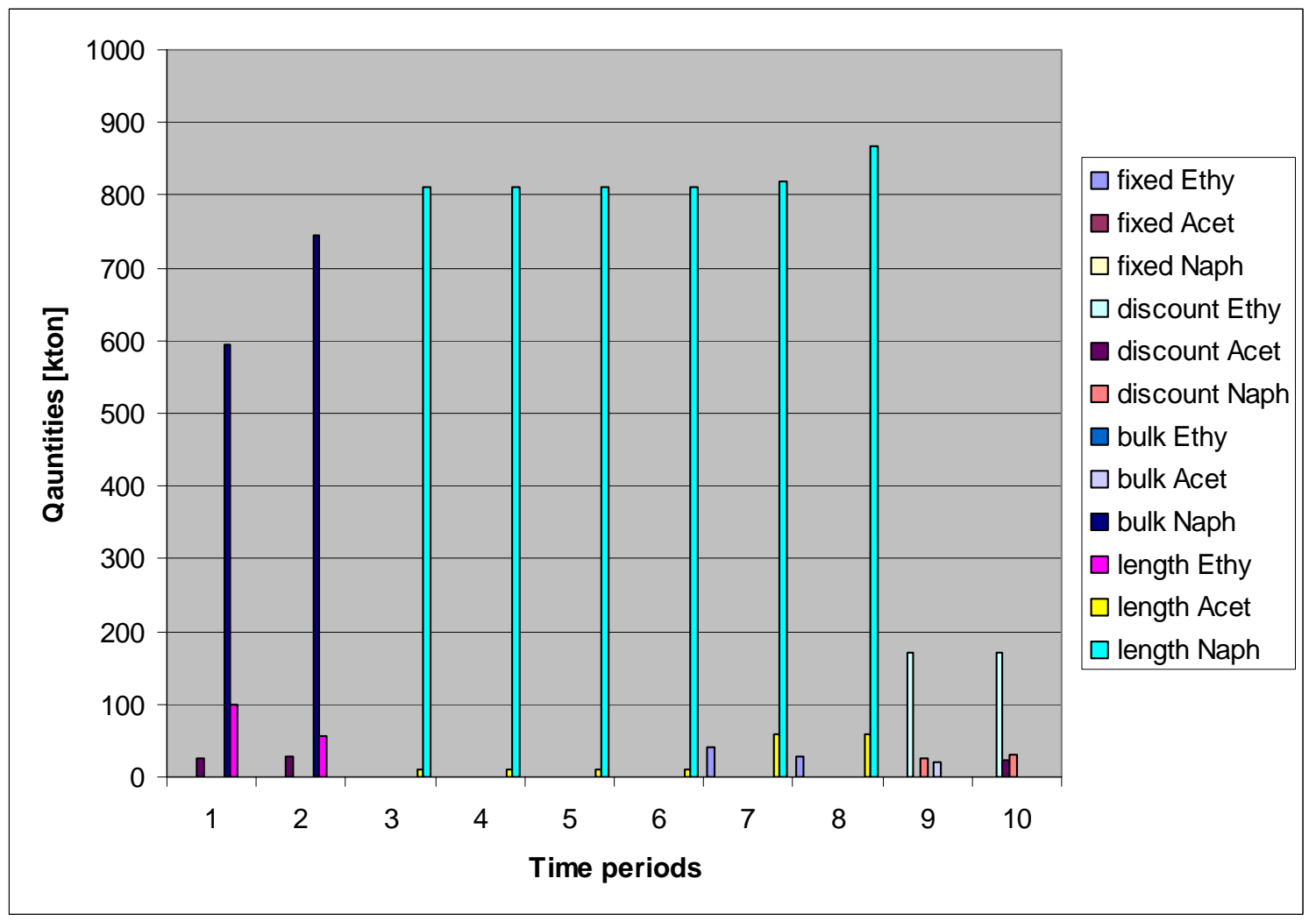

Figure 14. Decision of contracts with suppliers in case 2 in Example 2.

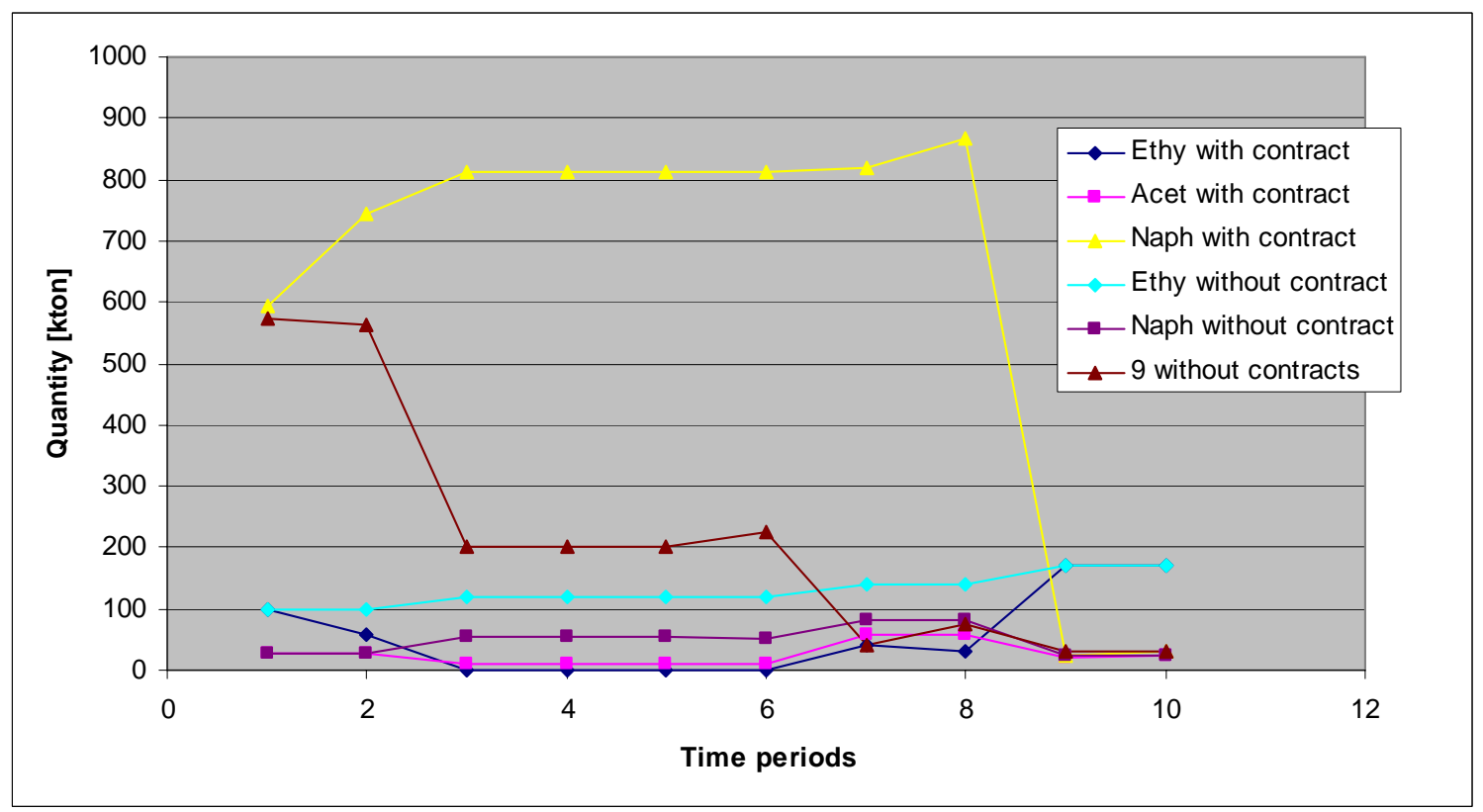

Figure 15. Amount of raw material bought in cases 1 and 2 in Example 2. 
Figure 16 shows a comparison of the distribution of revenues and costs in both cases. The higher profit in the second case is due to a larger level of sales (i.e. revenues). Difference from example 1 lies in a drop of purchase costs. In this example the capacity of the system allows for a larger volume of sales with the resulting increase in all costs. That can also be seen in Figure 17 comparing the percentage of demand satisfaction. In the case of making contracts the demand satisfaction is clearly improved.

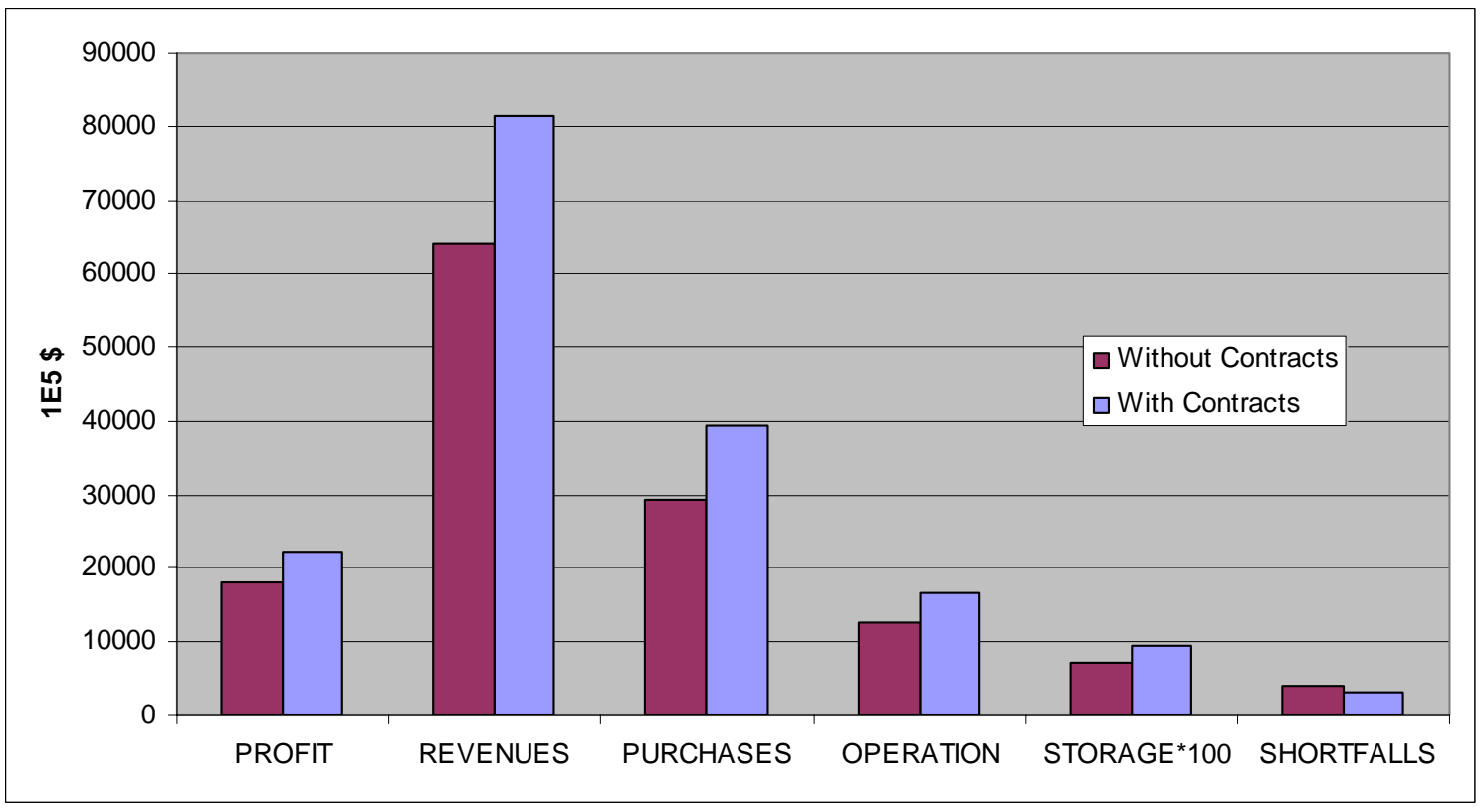

Figure 16. Comparison of revenues and costs in cases 1 and 2 in Example 2. 


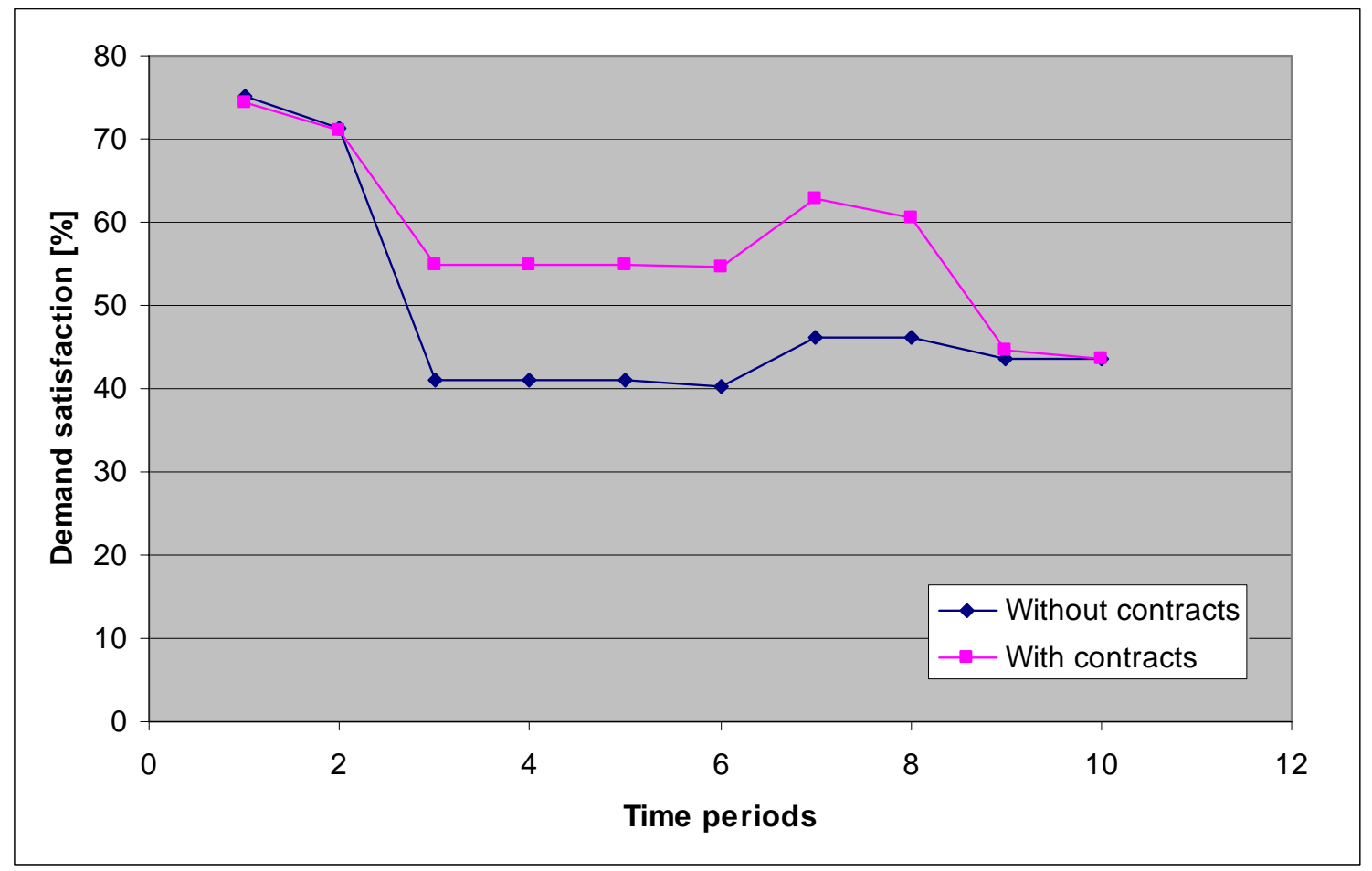

Figure 17. Demand satisfaction per time period in cases 1 and 2 in Example 2.

Figure 18 shows the contracts that are selected to purchase raw materials in case 4 , the long-term problem with possibility of capacity expansion. Figure 19 shows comparatively the total amounts purchased per period in cases 3 and 4 . As in the first two cases, the biggest difference between cases 3 and 4 is also the increase in the purchase of naphtha. 


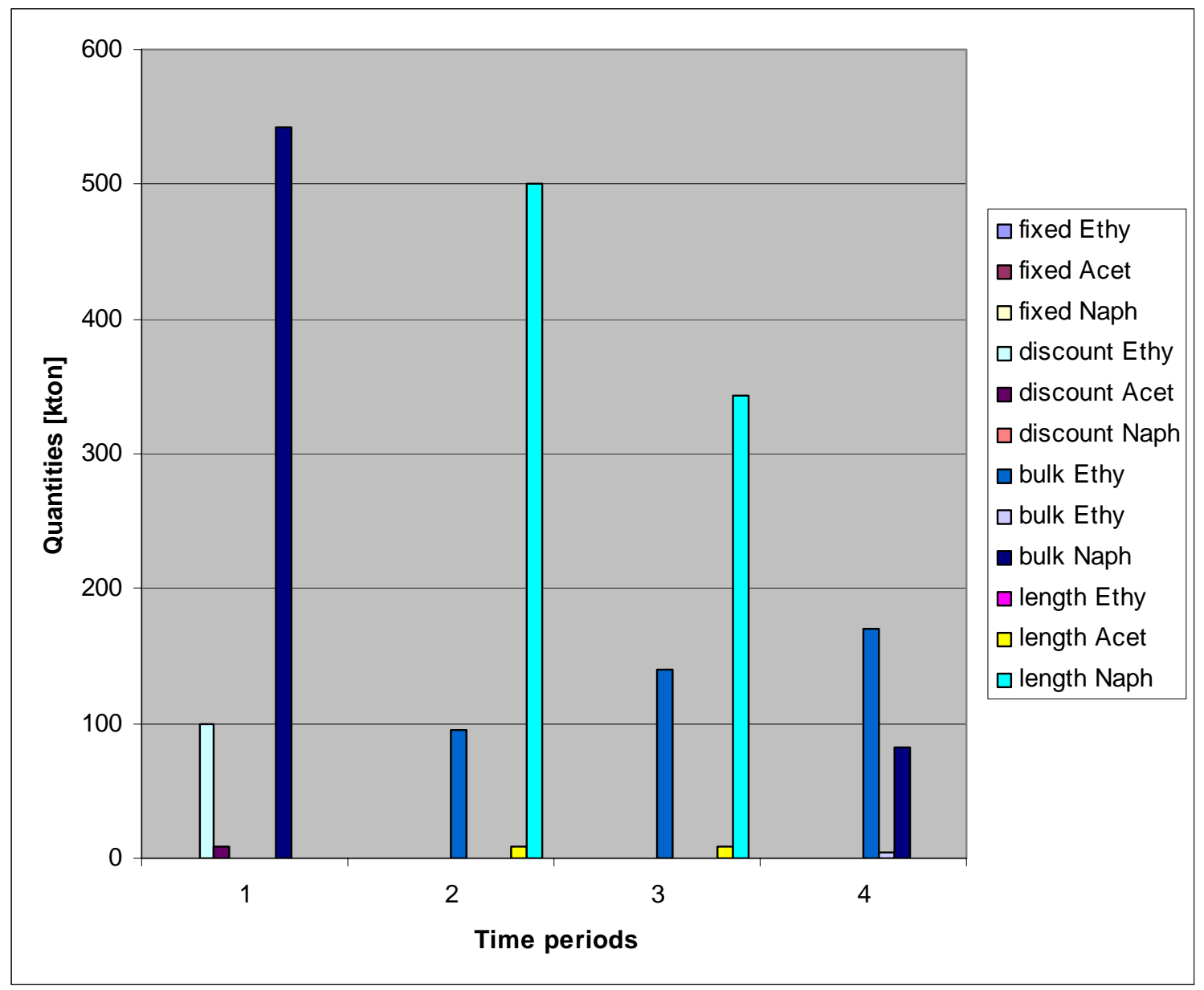

Figure 18. Decision of contracts with suppliers in case 4 in Example 2.

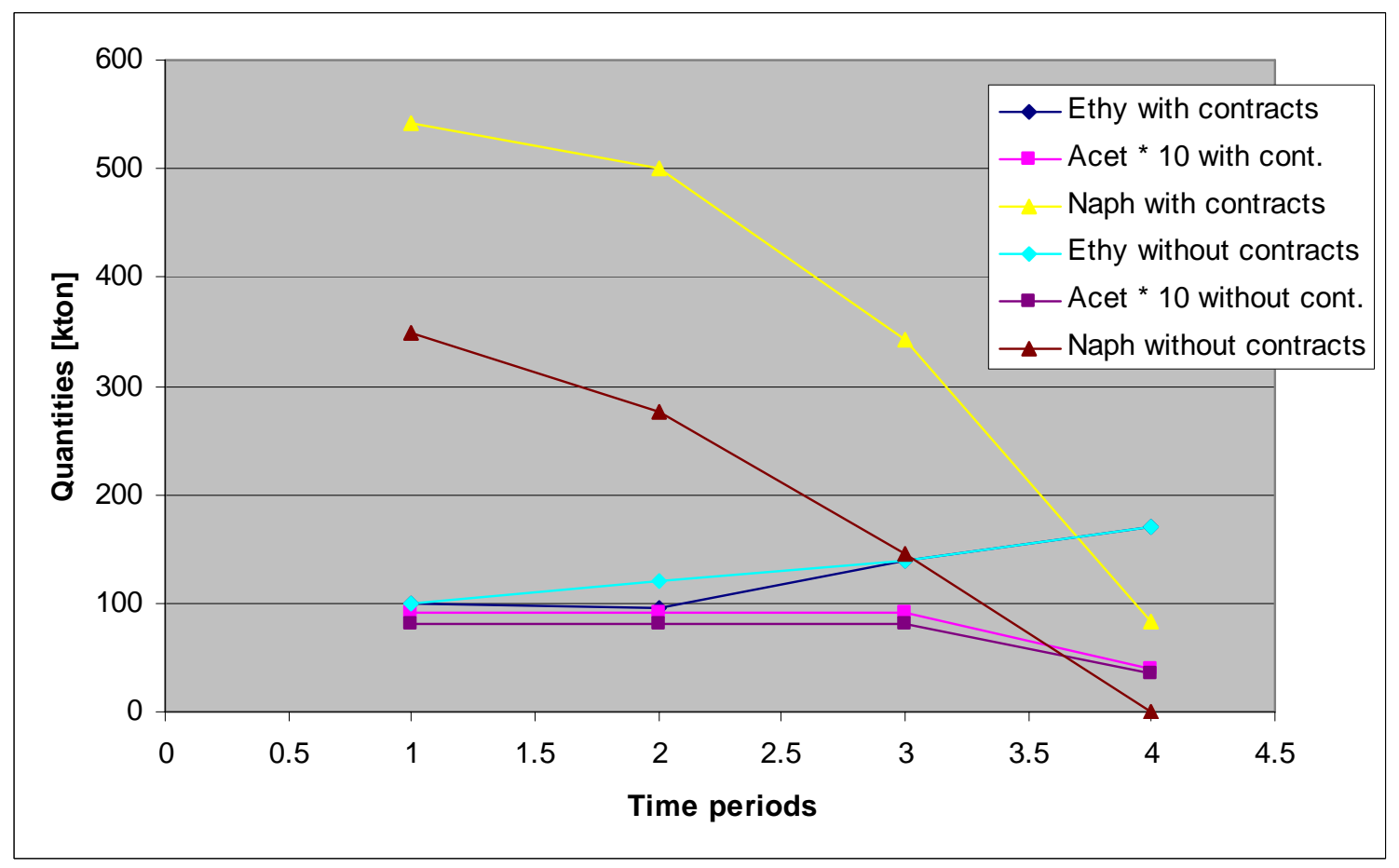

Figure 19. Amount of raw material bought in cases 3 and 4 in Example 2. 
Figure 20 shows a comparison between the NPV, the investments associated to the expansions and the costs in both cases. Again, the higher NPV in case 4 is due to a larger sales volume. This is evident from Figure 21, by comparing the percentage of demand satisfaction.

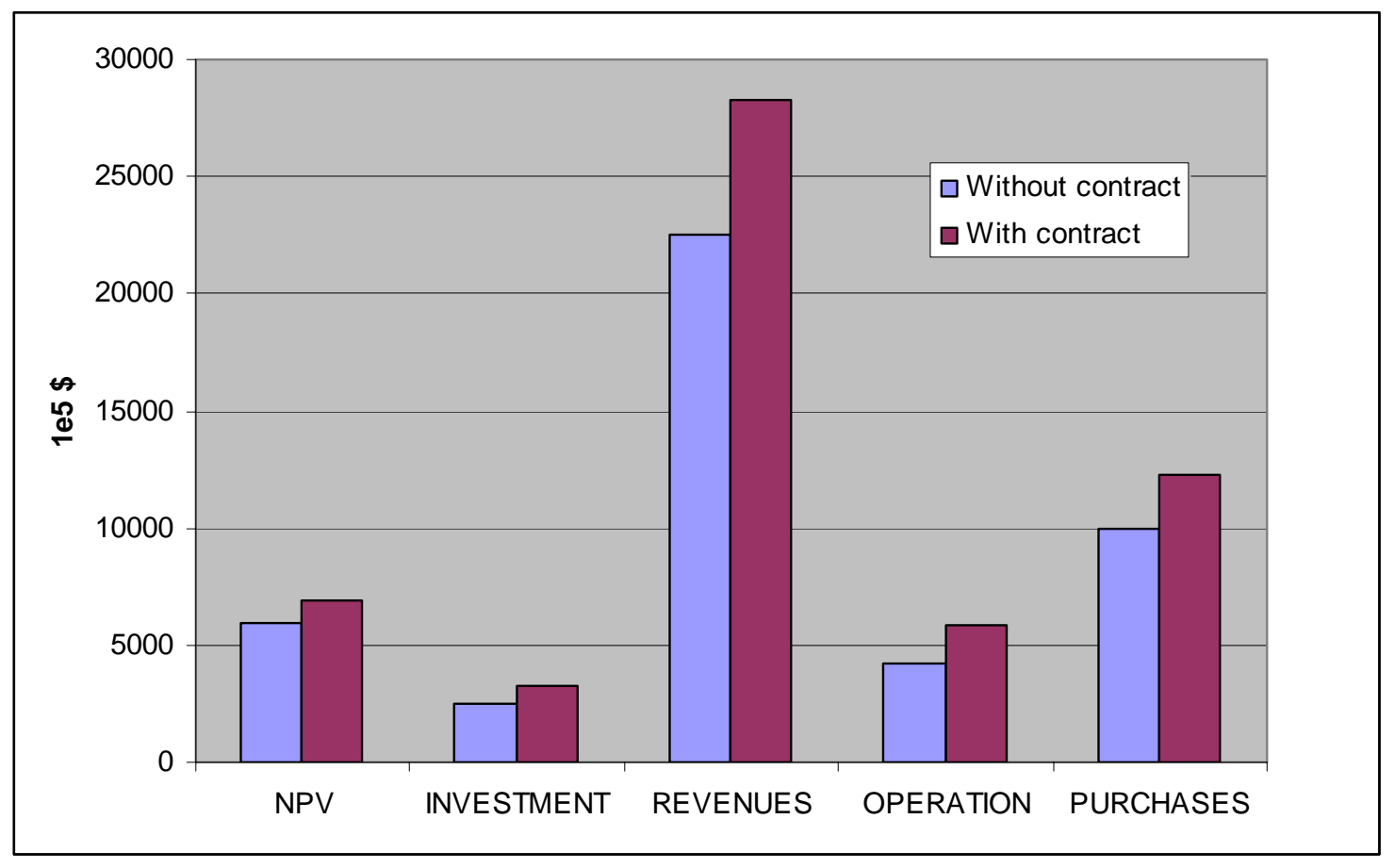

Figure 20. Comparison of investment and costs in cases 3 and 4 in Example 2.

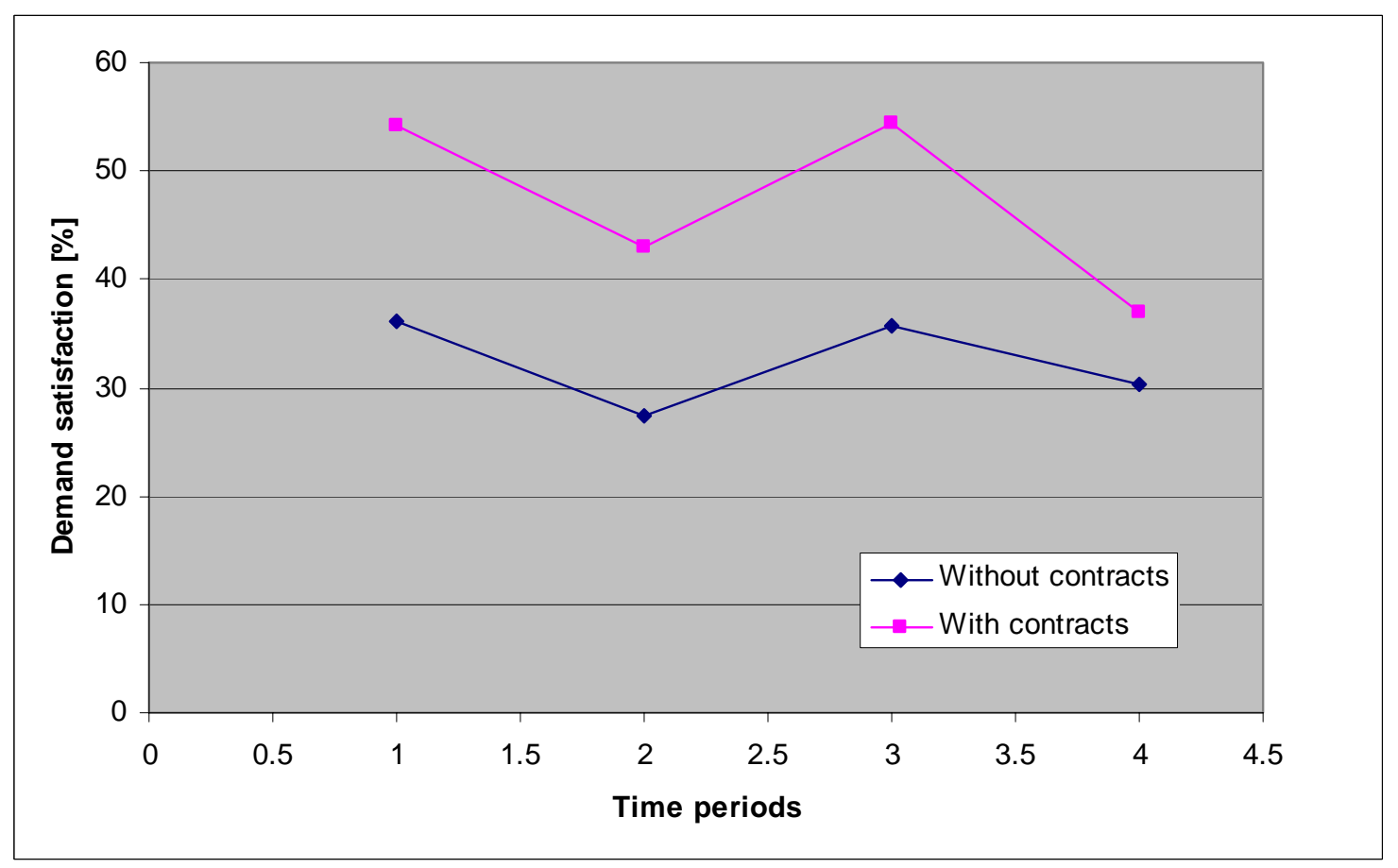

Figure 21. Demand satisfaction per time period in cases 3 and 4 in Example 2. 


\section{Conclusions}

New models have been presented in order to expand the scope of traditional models for the planning problem of a chemical processes, by considering the option of signing contracts. Four basic cases have been considered: fixed price, discount a certain amount, bulk discount and fixed duration contracts. The

proposed models were applied to both short-term and long-term planning problem, and for both suppliers and customers.

The results have clearly shown the benefits for the cases when the models were applied for the contracts for sales to customers. In the case of contracts signed with suppliers, direct benefits can be derived to the company, even in the deterministic case, owing to the economies of scale. Modeling contracts with customers should become more useful when considering stochastic problems as then the contracts have a decisive effect for reducing uncertainty. This is an interesting avenue to pursue.

\section{Acknowledgements}

The authors acknowledge the financial support provided by 'BK21' and 'Generalitat de Catalunya (FI programs)'.

\section{Appendix: Time period sets for the fixed length contract}

To illustrate the definition of sets $T_{t}^{p}, T_{\tau}^{p}$ in equations (47) and (49), We assume that the problem has six time periods ( $T=\{1,2,3,4,5,6\})$ and the contract lengths are of 1,2 and 3 periods ( $L C=\{1,2,3\}) . T_{t}^{p}$ is a set of time periods $\tau$ at which the contract is made in order to purchase the raw material in time period $t$ for length contract $p$. The values are as follows for $T_{t}^{p}$ :

$$
p=1, T_{1}^{1}=\{1\}, T_{2}^{1}=\{2\}, \ldots, T_{6}^{1}=\{6\}
$$


$p=2, T_{1}^{2}=\{1\}, T_{2}^{2}=\{1,2\}, \ldots, T_{5}^{2}=\{4,5\}, T_{6}^{2}=\{5\}$

$p=3, T_{1}^{3}=\{1\}, T_{2}^{3}=\{1,2\}, T_{3}^{3}=\{1,2,3\}, \ldots, T_{5}^{3}=\{3,4\}, T_{6}^{3}=\{4\}$ (A3)

If we buy some raw materials in time period 3 with the 3-period contract $(p=3)$, the contract must be made at time periods 1, 2 and 3 (see Fig. A1, a). The purchase amount $P_{j 4}^{l}$ of raw material $j$ in time period 4 is the summation of the amount $P_{j 44}^{l 1}$ with 1-period contract, the amount $P_{j 34}^{l 2}$ and $P_{j 44}^{l 2}$ in 2 period contract, and the amount $P_{j 24}^{13}, P_{j 34}^{l 3}$, and $P_{j 44}^{13}$ (see Fig. A1. b). Equation (48) represents the amount of raw materials purchased in time period $t$.

On the other hand, $T_{\tau}^{p}$ is a set of time periods $t$ in which the raw material is purchased with length contract $p$ made at time period $\tau$ :

$$
\begin{aligned}
& p=1, T_{1}^{1}=\{1\}, T_{2}^{1}=\{2\}, \ldots, T_{6}^{1}=\{6\} \\
& p=2, T_{1}^{2}=\{1,2\}, T_{2}^{2}=\{2,3\}, \ldots, T_{4}^{2}=\{4,5\}, T_{5}^{2}=\{5,6\} \\
& p=3, T_{1}^{3}=\{1,2,3\}, T_{2}^{3}=\{2,3,4\}, \ldots, T_{4}^{3}=\{4,5,6\}
\end{aligned}
$$

If we make a 2-period contract at time period 2, we must buy some material in time period 2 and 3 (see Fig. A1. c). Equation (49) expresses the terms of length contract described previously in the paper. For example, the cost of raw materials purchased at time period 5 with 3-period contract is the multiplication of the amounts purchased at time period 5 and the prices of contract made at time periods 3, 4 (see Fig. A1. d). 


\begin{tabular}{|c|c|c|c|c|c|c|c|}
\hline \multicolumn{2}{|c|}{ Contract } & \multicolumn{6}{|c|}{ Time period } \\
\hline Length & Price & 1 & 2 & 3 & 4 & 5 & 6 \\
\hline \multirow{6}{*}{1} & $\varphi_{j 1}^{11}$ & $P_{j 11}^{l 1}$ & & \multirow{6}{*}{$P_{j 33}^{i 1}$} & & \multirow{6}{*}{$P_{j 55}^{i 1}$} & \\
\hline & $\varphi_{j 2}^{11}$ & & $P_{j 22}^{l 1}$ & & & & \\
\hline & $\varphi_{j 3}^{11}$ & & & & & & \\
\hline & $\varphi_{j 4}^{11}$ & & & & $P_{j 44}^{i 1} \mathrm{~b}$ & & \\
\hline & $\varphi_{j 5}^{11}$ & & & & & & \\
\hline & $\varphi_{j 6}^{11}$ & & & & & & $P_{j 66}^{l 1}$ \\
\hline \multirow{5}{*}{2} & $\varphi_{j 1}^{2}$ & $P_{j 11}^{l 2}$ & $P_{j 12}^{l 2}$ & & \multirow{5}{*}{$\begin{array}{l}P_{j 34}^{l 2} \\
P_{j 44}^{l 2}\end{array}$} & & \\
\hline & $\varphi_{j 2}^{2}$ & & $P_{j 22}^{l 2}$ & $P_{j 23}^{l 2} \mathrm{c}$ & & & \\
\hline & $\varphi_{j 3}^{2}$ & & & $P_{j 33}^{l 2}$ & & & \\
\hline & $\varphi_{j 4}^{2}$ & & & & & $P_{j 45}^{l 2}$ & \\
\hline & $\varphi_{j 5}^{2}$ & & & & & $P_{j 5 S}^{l 2}$ & $P_{j 56}^{l 2}$ \\
\hline \multirow{4}{*}{3} & $\varphi_{j 1}^{3}$ & $P_{j 11}^{l 3}$ & $P_{j 12}^{l 3}$ & $P_{j 13}^{i 3} \mathrm{a}$ & & & \\
\hline & $\varphi_{j 2}^{3}$ & & $P_{j 22}^{l 3}$ & $P_{j 23}^{i 3}$ & $P_{j 23}^{l 3}$ & & \\
\hline & $\varphi_{j 3}^{3}$ & & & $P_{j 33}^{l 3}$ & $P_{j 34}^{l 3}$ & $P_{j 35}^{l 3} \mathrm{~d}$ & \\
\hline & $\phi_{j 4}^{3}$ & & & & $P_{j 44}^{l 3}$ & $P_{j 45}^{l 3}$ & $P_{j 46}^{l 3}$ \\
\hline
\end{tabular}

Figure A1. Length contract example with 6 time periods.

\section{Nomenclature}

Indices

subscripts

$\begin{array}{ll}i & \text { process } \\ j & \text { chemical } \\ k & \text { type of market } \\ t & \text { time period } \\ \tau & \text { time period of the contract signature }\end{array}$

superscripts

$C$ type of contract

$L \quad$ lower bound

$p \quad$ duration of the length contract

$U \quad$ upper bound

Sets

C types of contracts

I processes

$I_{j} \quad$ process that consume chemical $j$

$J_{i} \quad$ chemicals involved by process $i$

$J M_{i} \quad$ main products of process $i$

$J P \quad$ products

$J R \quad$ raw materials

LC contract lengths 


$\begin{array}{cl}O_{j} & \text { processes that produce chemical } j \\ T & \text { time periods } \\ T_{t}^{p} & \begin{array}{l}\text { time periods } \tau \\ \text { contract } p\end{array} \\ T_{\tau}^{p} & \begin{array}{l}\text { time periods }{ }^{t} \text { at which the contract is made to purchase material for length } \\ \text { time period } \tau\end{array}\end{array}$

Parameters

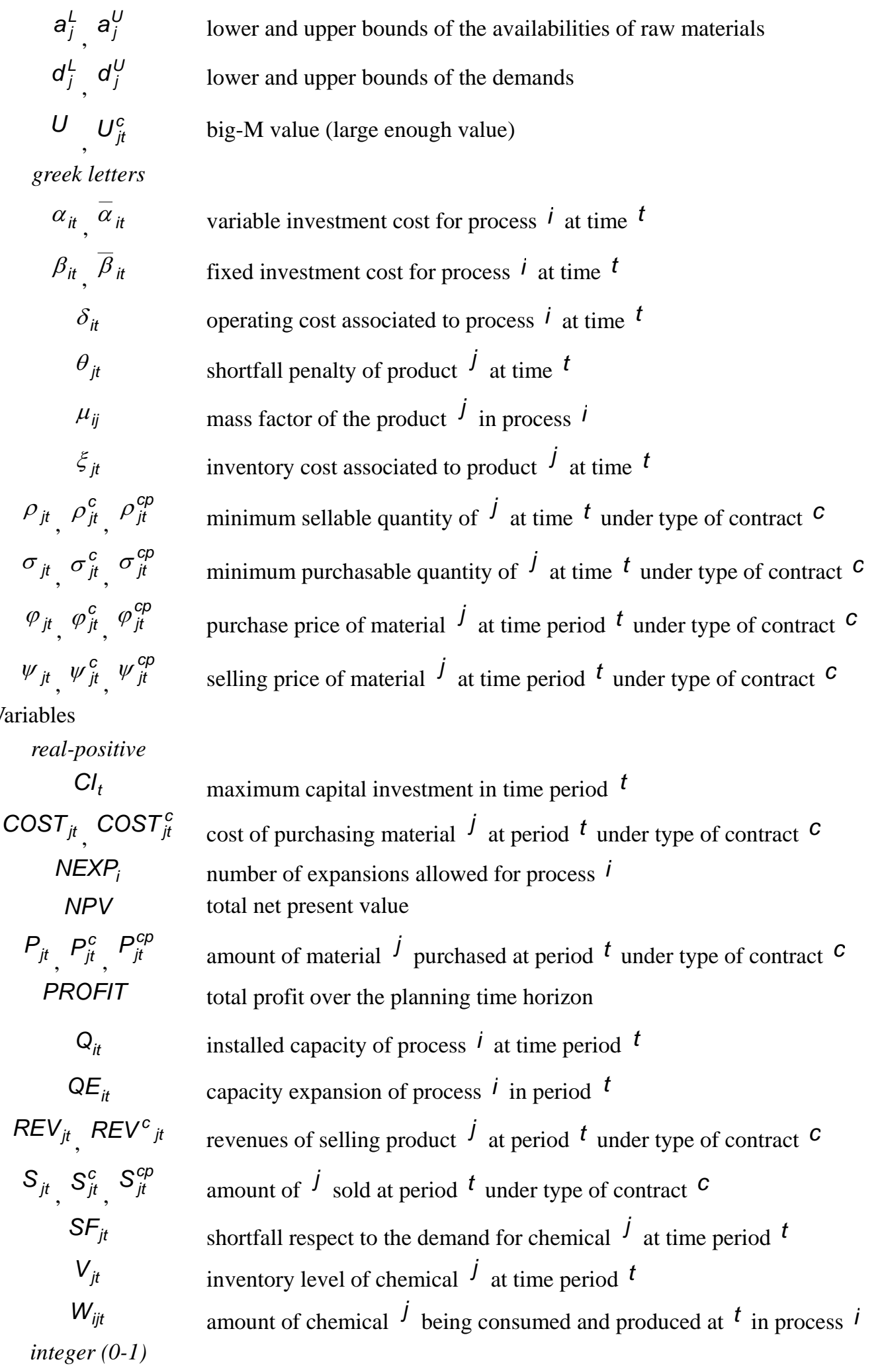




$\begin{array}{ll}w_{i t} & \text { if true, process }{ }^{i} \text { is expanded in period } t \\ y_{j t}^{c}, y_{j t}^{c p} & \text { if true, raw material }{ }^{j} \text { is purchased in period }{ }^{t} \text { using type of contract } c \\ z_{j t}^{c}, z_{j t}^{c p} & \text { if true, product }{ }^{j} \text { is sold in period }{ }^{t} \text { using type of contract } c\end{array}$

\section{References}

(1) Shah, N. Process industry supply chains: Advances and challenges. Computers and Chemical Engineering. 2005, 29, 1225-1235.

(2) Grossmann, I.E. "Enterprise-wide Optimization: A New Frontier in Process Systems Engineering," AIChE Journal. 2005, 51, 1846-1857.

(3) Grossmann, I. E.; Lee, S. Generalized disjunctive programming: nonlinear convex hull relaxation and algorithms. Computational Optimization and Applications. 2003, 26, 83-100.

(4) Sandholm, T. eMediator: A Next Generation Electronic Commerce Server. Computational Intelligence, Special issue on Agent Technology for Electronic Commerce. 2002, 18, 656-676.

(5) Goodwin, R.; Keskinocak, P.; Murthy, S.; Wu, F.; Akkiraju, R. Intelligent decision support for the esupply chain. In Artificial Intelligence for Electronic Commerce, AAAI Workshop 99. 1999, p. 770.

(6) Anupindi, R.; Bassok, Y. Supply Chain Contracts with Quantity Commitments and Stochastic Demand: Quantitative Models for Supply Chain Management. Norwell, MA: Kluwer Academic Publishers, 1999.

(7) Hull, J. Introduction to Futures and Options Markets. Englewood Cliffs, NJ: Prentice Hall,1995.

(8) Gupta, A.; Maranas, C. Market-based pollution abatement strategies: Risk management using emission option contracts. Industrial and Engineering Chemistry Research. 2003, 42, 802-810.

(9) Barbaro, A. F.; Bagajewicz, M. Use of inventory and option contracts to hedge financial risk in planning under uncertainty managing financial risk in planning under uncertainty. AIChE Journal. 2004, 50, 990-998. 
(10) Bonfill, A.; Bagajewicz, M. J.; Espuña, A.; Puigjaner, L. Risk Management in the Scheduling of Batch Plants under Uncertain Market Demand. Ind Industrial and Engineering Chemistry Research. 2004, 43, 741-750.

(11) Aseeri; Bagajewicz, M. J. New measures and procedures to manage financial risk with applications to the planning of gas commercialization in Asia. Computers and Chemical Engineering. 2004, 28, 2791-2821.

(12) Kallrath, J. Combined strategic and operational planning: An MILP success story in chemical industry. OR Spectrum. 2002, 24, 315-341.

(13) Schulz, E. P.; Diaz, M. S.; Bandoni, J. A. Supply chain optimization of large-scale continuous processes. Computers and Chemical Engineering. 2005, 29, 1305-1316.

(14) Chandra Prakash Reddy, P.; Karimi, I. A.; Srinivasan, R. Novel solution approach for optimizing crude oil operations. AIChE Journal. 2004, 50, 1177-1197.

(15) Balas, E. Disjunctive programming and a hierarchy of relaxations for discrete optimization problems. SIAM Journal of Algebraic Discrete Methods. 1985, 6, 466-486.

(16) Jackson, J. R.; Grossmann, I. E. High-level optimization model for the retrofit planning of process networks. Industrial and Engineering Chemistry Research. 2002, 41, 3761-3770.

(17) Sahinidis, N. V.; Grossmann, I. E.; Fornari, R. E.; Chathrathi, M. Optimization model for long range planning in the chemical industry. Computers and Chemical Engineering. 1989, 13, 1049-1063. 